\title{
Does Uncertainty Matter? \\ A Stochastic Dynamic Analysis of Bankable Emission Permit Trading for Global Climate Change Policy*
}

\author{
Fan Zhang ${ }^{1}$
}

\begin{abstract}
Emission permit trading is a centerpiece of the Kyoto Protocol which allows participating nations to trade and bank greenhouse gas permits under the Framework Convention on Climate Change. When market conditions evolve stochastically, emission trading produces a dynamic problem, in which anticipation about the future economic environment affects current banking decisions. In this paper, I explore the effect of increased uncertainty over future output prices and input costs on the temporal distribution of emissions. In a dynamic programming setting, a permit price is a convex function of stochastic prices of electricity and fuel. Increased uncertainty about future market conditions increases the expected permit price and causes a riskneutral firm to reduce ex ante emissions so as to smooth out marginal abatement costs over time. The convexity results from the asymmetric impact of changes in counterfactual emissions on the change of marginal abatement costs. Empirical analysis corroborates the theoretical prediction. I find that $1 \%$ increase in electricity price volatility measured by annualized standard deviation of percentage price change is associated with an average decrease in annual emission rate by $0.88 \%$. Numerical simulation suggests that high uncertainty could induce substantially early abatements, as well as large compliance costs, therefore imposing a tradeoff between environmental benefits and economic efficiency. Policy implications for designing an effective and efficient global carbon market are discussed.
\end{abstract}

World Bank Policy Research Working Paper 4215, April 2007

The Policy Research Working Paper Series disseminates the findings of work in progress to encourage the exchange of ideas about development issues. An objective of the series is to get the findings out quickly, even if the presentations are less than fully polished. The papers carry the names of the authors and should be cited accordingly. The findings, interpretations, and conclusions expressed in this paper are entirely those of the authors. They do not necessarily represent the view of the World Bank, its Executive Directors, or the countries they represent. Policy Research Working Papers are available online at http://econ.worldbank.org.

* I thank the World Bank Research Committee for funding, and Dr. Zmarak Shalizi and Philippe Ambrosi for helpful comments and suggestions.

\footnotetext{
${ }^{1}$ Author's affiliation: Harvard University, Cambridge, MA 02138, USA.

email: Fan_Zhang@ksgphd.harvard.edu
} 


\section{Introduction}

Cap-and-trade emission permit systems that allow permits to be traded over time (hereafter bankable emission permits trading or intertemporal emission trading) are witnessing growing regulatory interest as a cost-effective way to reduce total emissions. The grandest use for marketable permit trading is contained in Kyoto Protocol which allows participating nations to trade and bank greenhouse gas permits under the Framework Convention on Climate Change (Intergovernmental Panel on Climate Change, 1996). ${ }^{2}$ The U.S. sulfur dioxide $\left(\mathrm{SO}_{2}\right)$ emissions trading program established under Title IV of the 1990 Clean Air Act Amendments is one of the first, and by far the most extensive application of bankable emission permit trading. Under Title $\mathrm{IV}$, firms are not only allowed to transfer allowances for emission of $\mathrm{SO}_{2}$ among facilities, but also allowed to bank them for use in future years.

Despite the large interest in intertemporal emission trading, important theoretical and policy issues under this trading mechanism remain unexplored. In particular, although the theoretical literature on tradable emission permits has established an in-depth discussion regarding the efficiency and properties of their use since the early 1970s (Montgomery, 1972; Hahn, 1984; and see Titenberg [1985] and Cropper and Oates [1992] for thorough reviews), most of the literature considers trading between units, implicitly within a single time period. Theoretical analyses of intertemporal emission trading have only recently received attention (Rubin, 1996; Cronnshow and Kruse, 1996; Kling and Rubin, 1997; Schennach, 2000; Yates and Cronshaw, 2001; Leiby and Rubin, 2001; Stevens and Rose, 2002; Sedio and Marland, 2003; Maeda, 2004; Stranlund, et al., 2005; van Steenbergh, 2005; Feng and Zhao, 2006; Wirl, F. 2006). With few exceptions, ${ }^{3}$ these studies assume firms have perfect foresight. There has been no formal analysis of the impact of output market uncertainty in the intertemporal permit literature.

No environmental policy is implemented in the ideal world of certainty. In fact, uncertainty is a prevailing feature of many environmental policies, especially the global climate change program. For example, countries subject to Kyoto Protocol have to deal with various uncertainties over time, including the demand for energy, the speed and arrival of technology development, the engagement of other countries in the market, the total emission cap, and the interest rate etc. Revenue uncertainty, acting together with technological and policy uncertainty, will have important implications for countries' intertemporal carbon management, including those decisions on investment in low-carbon and renewable technologies.

The purpose of this paper is to explore the effects of uncertainty on the temporal pattern of emission trading. In particular, we ask how a mean-preserving increase in output price volatility would affect firms' banking and abatement decisions. I develop a stochastic dynamic optimization model of a risk-neutral price-taking firm, which uses high- and/or low-carbon fuel

\footnotetext{
${ }^{2}$ In particular, Kyoto Protocol sets legally binding emissions targets and timetables for Annex B countries. Together, Annex B countries must reduce their emissions of six greenhouse gases by at least $5 \%$ below 1990 levels over the commitment period 2008 - 2012. One Annex B country is allowed to purchase the rights to emit greenhouse gases from other Annex B countries. The protocol also allows for banking of permits, or mitigation in excess of commitments in some periods, with the prospect of mitigation at levels lower than commitments at some future date. Borrowing, however, is not explicitly mentioned.

${ }^{3}$ Studies that mention uncertainties include Schennach (2000), Feng and Zhao (2006).
} 
to produce electricity. Current prices are known, but the future prices evolve stochastically. I show that in equilibrium, the marginal abatement costs of all firms are equalized with the permit price in each period; for each firm, the expected present marginal abatement costs are also equalized across time periods. When future compliance costs are expected to increase, firms will demand positive permits, bidding up the permit price (and therefore marginal abatement cost) until current and expected future prices are equal.

The permit price is subject to output price shocks, which alter firms' abatement costs by changing the industry-wide counterfactual emission level. ${ }^{4}$ I prove analytically that the permit price, as well as firms' marginal abatement cost, is a convex function of the electricity price. By Jensen's inequality, this leads to a positive relationship between the marginal abatement cost and the increase in volatility of the stochastic variable. This convexity relationship results from the asymmetric impact of electricity price change on the change in marginal abatement cost. Because marginal abatement cost is convex (as long as the marginal productivity is decreasing), when the electricity price increases (and therefore the abatement level increases), the marginal abatement cost increases faster than it decreases when the electricity price falls. When uncertainty is pronounced, very high and very low electricity prices become more likely, and this asymmetric impact becomes more salient. In the presence of extreme electricity prices, firms would have a much higher incentive to reduce ex ante emission and accumulate permits so as to smooth out the marginal abatement costs over time. This conclusion holds whether the output market is perfectly competitive or not. In addition, the model is extended to allow uncertainties to enter through input costs and industry wide productivity. The conclusion follows the same line.

In the second part of the paper, I empirically test the theoretical prediction using data observed from the U.S. $\mathrm{SO}_{2}$ allowance trading market from 1996 to 2004. Empirical analysis shows that one percent increase in electricity price volatility measured by annualized standard deviation of percentage price change is on average associated with a $0.88 \%$ decrease in annual emission rate. Overall, increased price volatility induced by electricity market restructuring over the last decade may explain $8-11 \%$ of the total amount of the banked allowances during Phase I of the U.S. $\mathrm{SO}_{2}$ trading program.

To estimate the impact of market uncertainty on social welfare, I simulate the banking pattern, emission stream and the time path of permit price resulting from various degrees of output price uncertainties. Numerical results are quite suggestive and consistent with the empirical evidence. The results indicate that high uncertainty may generate substantially large compliance costs in the early years, deterring new entrants and cause efficiency loss; from the environment perspective, uncertainty encourages overcopmliance in early years; when a pollutant such as a greenhouse gas, creates stock damage, benefits from early abatement could be substantial. ${ }^{5}$

The remainder of the paper is organized as follows: Section II provides a literature review. Section III develops a firm model of intertemporal emission trading and derives the relationship

\footnotetext{
${ }^{4}$ Counterfactual emission is the level of emission that would prevail when there is no environmental regulation.

${ }^{5}$ Currently, the transfer of unused allowances from the period $2005-2007$ to the first commitment period under the Kyoto Protocol, i.e. 2008-2012, is not allowed under an EU-wide ban on banking (except for Poland and France), which from an environmental point of view, seems to be a troubling decision.
} 
between ex ante emissions and uncertainty; Section IV presents the empirical model and the estimation results. Section $\mathrm{V}$ discusses numerical simulation, welfare analysis and policy implications and Section VI concludes the paper.

\section{Background and Literature Review}

This paper is related to two strands of literature, that on intertemporal emission permit trading and that on capital investment under uncertainty. Previous theoretical investigations of intertemporal permit trading generally do not consider the presence of uncertainty. Rubin (1996) shows that when firms are allowed to freely bank and borrow permits across time, permit prices and pollutant emissions must evolve following the deterministic path described by Hotelling's rule. Within a similar framework, Kling and Rubin (1997) compare the emission path firms would choose with the social optimal solution and show that when borrowing and banking are allowed private solutions diverge from social optimum. Cronnshow and Kruse (1996) show that in a competitive tradable and bankable permit market, a competitive equilibrium exists and achieves aggregate emission targets for the least system cost.

Schennach's (2000) research is a first effort to study the implications of output market uncertainty on individual firms' emission trading strategy. Among other conclusions, Schennach (2000) suggests that the higher the expected electricity price, the lower the emissions in earlier periods. Schennach (2000) also emphasized the role of the non-negativity constraint, a special feature associated with the U.S. Acid Rain Program, arguing that the expectation on a potential stockout of the banked permits may induce reduction of emissions in earlier periods. Feng and Zhao (2005) explore efficiency of the permit system when there is information asymmetry between regulatory agency and the regulated firm regarding uncertainty and find that the higher the degree of asymmetry, the more potential benefits form a bankable permit regime. While these papers constitute important steps toward an understanding of the potential consequences of uncertainty, they do not answer the question of how increased output market price volatility would modify the path of emissions. After all, it is the significant variation, not the level of prices that defines a volatile market.

In spirit, this paper is closer to Hartman (1972) and Abel $(1983,1985)$. In these models, the presence of adjustment costs, together with a constant-returns-to-scale technology, make the marginal revenue product of capital a convex function of output price. Therefore, increased uncertainty about the future price of output increases the expected marginal revenue product for a competitive firm and hence increases the intensity of investment. Similarly, in this paper, I demonstrate the positive relationship between electricity price uncertainty and the expected marginal value of an permit by applying Jensen's inequality for a convex function. However, the analysis of the marginal value of a permit has no direct analogue to the problems in the capital investment literature. In addition, I present the analysis in a more general framework, without assumptions of constant-returns-to-scale and perfect competition in the output market.

Neither the theory nor the empirical assessment of the implications of the increased output market uncertainty for emission trading has been fully examined in the intertemporal trading literature. Therefore, this paper makes two specific contributions. First, I introduce uncertainty into the intertemporal trading model, which is theoretically more interesting and empirically 
more relevant. In this model, firms' decisions regarding permit trading is an ex ante choice in the sense that optimal emissions and permit banking decisions depend not only on current but also on expectation of future output and input prices. Second, I empirically test the theoretical prediction in a real trading program. To the best of my knowledge, this is the first attempt to quantitatively estimate the effects of uncertainty on emission trading based on actual market data. Although empirical analysis is conducted in the context of the U.S. $\mathrm{SO}_{2}$ allowance trading program, the conclusion is general enough to be extended to the analysis of global carbon trading program.

\section{Modeling Framework}

This section contains the basic theory of intertemporal permit trading under uncertainty. I begin by setting up a firm's dynamic optimization problem, and then state and prove Proposition 1 and Lemma 1 on the relationship between uncertainty, and banking/emissions. I then go on to show how conclusions can be affected by imperfect competition in the permit and output markets and returns to scale of production technology.

\section{III.(i) A Firm Model of Intertemporal Permit Trading Under Uncertainty}

Consider a risk neutral firm that uses adjustable levels of low- and high-carbon fuel to produce electricity. In each time period, the firm decides the electricity output $\left(g_{t}\right)$ chooses the mix of low- and high-carbon fuel ( $l_{t}$ and $\left.h_{t}\right)$, and the amount of permits to buy $\left(x_{t}>0\right)$ or sell $\left(x_{t}<\right.$ 0 ) to maximize its discounted present profits for a constrained level of emissions. Uncertainty exists in the supply and demand for electricity. Suppose this uncertainty is characterized by electricity prices $P e$, which is a random variable that follows a Markov process. The probability law of $P e$ is known to all firms. At the start of each period $t$, the firm observes electricity price $\left(P_{e t}\right)$, permit price $\left(P_{a t}\right)$, the price for low- and high-carbon fuel $\left(P_{l t}\right.$ and $\left.P_{h t}\right)$, and the initial endowment of permits which is the sum of permits issued by the government at current period $\left(A_{t}\right)$ and the amount of banked permits carried from the previous period $\left(B_{t}\right)$. Refer to Table I for a thorough description of all model parameters used in the section.

Firms are facing a dynamic optimization problem because choosing how many permits to save for the future has to be made before uncertainties over future prices are resolved. Assuming that firms are price takers in all markets, I model individual firm behavior as an intra-firm game. Taking the strategies of other firms as given, each firm picks a strategy in each time period that is optimal from the firm's perspective in that period. The firm's strategy is thus a map from the Markov state $\Lambda_{t}=\left\{P_{t}, A_{t}, B_{t}\right\}$ to choose variables $\left\{l_{t}, h_{t}, x t\right\}$, where $P_{t}$ is a price vector, i.e. $P_{t}=$ $\{P e t, P a t, P l t, P h t\}$.

I assume firms employ three compliance strategies: abating emissions through blending or switching to low-carbon fuel, purchasing allowances in addition to initial allocation, and adjusting output levels. Other capital intensive strategies such as scrubbing, re-powering or permanently retiring a facility are not considered because regulatory, financial and other uncertainties in today's volatile energy markets provide firms incentive to avoid capital intensive investment as long as possible. 
Let $V_{i}\left(P_{t}, B_{t}, A_{t}\right)$ denote firm i's value at time $t$. The firm's maximization problem can be written as:

$$
\begin{array}{cl}
V_{i}\left(P_{t}, B_{t}, A_{t}\right) \equiv \max _{l_{i t}, h_{i t}, x_{i t}}\left\{P_{e t} g_{i t}\left(l_{i t}, h_{i t}\right)-c_{i t}\left(l_{i t}, h_{i t}\right)-P_{a t} x_{i t}+\beta E_{t}\left[V_{i(t+1)}\left(P_{t+1}, B_{i(t+1)}, A_{i(t+1)}\right)\right]\right\} \\
\text { s.t. } & B_{i(t+1)}=A_{i t}+B_{i t}-e_{i t}\left(l_{i t}, h_{i t}\right)+x_{i t} \\
B_{i(t+1)} & \geq 0
\end{array}
$$

where $\beta$ is the discount ratio. In a discrete-time setting, $\beta=1 /(1+r)$ and $r$ is the risk-free interest rate. ${ }^{6} \mathrm{E}[\cdot]$ is the expectations operator. Eq.(2) is the state equation and defines the stock of banked permits in period $t$. Eq.(3) corresponds to the non-negativity constraint,i.e. borrowing against future emission reductions is not allowed. For simplicity, hereafter I suppress unit index $i$.

The production function with low- and high-carbon fuels as two distinct inputs is represented by $g(l, h)$, which is assumed to be concave, increasing in both arguments, homogenous of degree 1 , and twice differentiable everywhere. ${ }^{7}$ Most of the previous studies assumed output as given (Rubin [1996], Arimura [2002]). In competitive electricity markets, an assumption of fixed output seems untenable. In this model, I assume that producers may alter the output level as a way to meet the required emission standard.

$c(l, h)$ is the cost function. When a firm undertakes production, it incurs costs that can be described in terms of three components: (1) fuel costs, (2) adjustment costs associated with fuelblending or fuel-switching, and (3) other fixed costs including capital costs for mixing fuel. Once the binary choice determining whether or not to switch/blend fuel has been made, this sunk cost will have no impact on the factor input ratio. Thus I do not explicitly take account of the initial capital cost in this analysis. ${ }^{8}$

For the model to be tractable, I assume that the adjustment costs are continuous and linear in l. ${ }^{9}$ Specifically, I combine the variable adjustment cost and purchasing cost of low-carbon fuel as an augment cost and represent the cost function as a standard linear one.

$$
c(l, h)=P_{l} l+P_{h} h
$$

where $P_{l}$ is the sum of both purchasing cost and the variable adjustment cost of low-carbon fuel. Implicitly, there is $P_{l}>P_{h}$.

Finally, I denote the emission function as $e(l, h)=\gamma\left(\delta_{l} l+\delta_{h} h\right)$, where $\delta_{l}$ and $\delta_{h}$ are the carbon contents of low- and high-carbon fuel $\left(\delta_{l}<\delta_{h}\right)$, and $\gamma$ is the converting rate from carbon to carbon dioxide.

\footnotetext{
${ }^{6}$ In fact, interest rate itself imposes another uncertainty on the optimization problem. To focus the attention on the effect of output market uncertainty, here I assume $r$ remains constant.

${ }^{7}$ To include labor $(a)$ and capital $(k)$ inputs in the production function is straightforward and yields an almost identical analysis.

${ }^{8}$ Philippe Ambrosi made another point that fuel switching may also be linked to the decision to operate one power plant rather than another, and there are no sunk costs involved.

${ }^{9}$ As will be shown later, the abatement cost is strictly convex.
} 
To analyze the above constrained stochastic dynamic optimization problem, consider a firm that is in place for two periods $t=1,2$. The Kuhn-Tucker sufficient conditions for a maximum at $\left(h^{*}, I^{*}, x^{*}, \varpi^{*}\right)$ yield the following first-order conditions:

$$
\begin{aligned}
& P_{a 1}=\beta E_{1}\left[V_{B_{2}^{*}}\right]+\varpi^{*} \\
& P_{e 1} g_{i}{ }^{\prime}{ }_{f_{1}^{*}}=c^{\prime}{ }_{f_{1}^{*}}+\left(\beta E_{1}\left[V_{B_{2}^{*}}\right]+\varpi^{*}\right) e^{\prime}{ }_{f_{1}^{*}} \quad f=l, h \\
& A_{1}+B_{1}+x_{1}^{*}-e_{1}^{*} \geq 0, \varpi^{*} \geq 0, \varpi^{*}\left(A_{1}+B_{1}+x_{1}^{*}-e_{1}^{*}\right)=0
\end{aligned}
$$

where $\varpi^{*}$ is the multiplier associated with inequality (3). $\varpi^{*}>0$ if and only if the non-negativity constraint is binding, i.e. $A_{1}+B_{1}+x_{1}-e^{*}{ }_{1}>0$ implies $\varpi^{*}=0$.

Eq.(4) is the Euler-intertemporal condition. ${ }^{10}$ Eq. (5) discloses that producers choose the optimal levels of fuel so that the fuel's marginal value product equals its marginal cost. The marginal cost includes both the direct production cost and the opportunity cost of surrendering the option to use permits in a future period. Therefore, expectations on the marginal value of a unit of allowance in next period $\left(E_{1}\left[V_{B 2}\right]\right)$ affect current emission decisions.

The second-period optimization problem is

$$
\begin{array}{ll} 
& V_{2}=\max _{l_{2}, h_{2}, x_{2}} P_{e 2} g\left(h_{2}, l_{2}\right)-c\left(h_{2}, l_{2}\right)-P_{a 2} X_{2} \\
\text { s.t. } & A_{2}+B_{2}-e\left(h_{2}, l_{2}\right)+x 2=0
\end{array}
$$

Eq.(8) shows that firms deplete the pmiert bank in the terminal period. The Lagrangian is

$$
L=P_{e 2} g_{i}\left(h_{2}, l_{2}\right)-c\left(h_{2}, l_{2}\right)-P_{a 2} x_{2}+\lambda_{2}\left(A_{2}+B_{2}-e\left(h_{2}, l_{2}\right)+x_{2}\right)
$$

The solution $\left(l_{2}^{*}, h_{2}^{*}, x_{2}^{*}, \lambda_{2}^{*}\right)$ is described by the following first-order equations:

$$
\begin{aligned}
& P_{a 2}=\lambda_{2}^{*} \\
& P_{e 2} g_{i}{ }^{\prime}{ }_{f_{2}^{*}}^{*}=c^{\prime}{ }_{f_{2}^{*}}^{*}+\lambda_{2}^{*} e_{f_{2}^{*}}^{\prime} \quad f=l, h
\end{aligned}
$$

$\lambda_{2}$ can be interpreted as the shadow value of a unit of banked permit in period-2. Eq.(10) says that firms will buy or sell permits such that the shadow value of the marginal permit equals to its market price. The optimal input mix $\left(l_{2}^{*}, h_{2}^{*}\right)$ is given by Eq.(11).

An important feature of the above optimal solution is that it is independent of the level of banked permits $\left(B_{2}\right)$. The value function in period 2 is only linearly linked to $B_{2}$ through the profit function. Specifically, the value function in Eq.(7) can be written as ${ }^{10} g_{f}{ }_{f}, c_{f}^{\prime}, e_{f}^{\prime}(f=l, h)$ represent the marginal productivity, marginal production cost, and marginal emission rate of
the two types of fuel. Hereafter, ' represents the calculation of a derivative. 


$$
V_{2}=P_{e 2} g\left(h_{2}^{*}\left(P_{2}\right), l_{2}^{*}\left(P_{2}\right)\right)-c\left(h_{2}^{*}\left(P_{2}\right), l_{2}^{*}\left(P_{2}\right)\right)-P_{a 2}\left[A_{2}+B_{2}-e\left(h_{2}^{*}\left(P_{2}\right), l_{2}^{*}\left(P_{2}\right)\right)\right]
$$

where $P_{2}=\left\{P_{e 2}, P_{l 2}, P_{h 2}, P_{a 2}\right\}$. Differentiating Eq.(12) with respect to $B_{2}$ we get the marginal revenue product of permits:

$$
V_{B 2^{*}}=P_{a 2}
$$

Substituting this expression for $V_{B 2}$ into Eq.(4) leads to a non-arbitrage pricing formula:

$$
P_{a 1}=\beta E\left(P_{2}\right)+\varpi^{*}
$$

The right hand side of Eq.(14) is the expected return of holding one unit of permit. It consists of two components: expected present permit price in period 2 and a convenience yield $\varpi^{*}$. The left hand side of the equation represents the opportunity cost of carrying an additional unit of permit, which is an instantaneous gain from selling it in the spot market. To simplify notations while not affect the generally conclusions on the relationship between uncertainty and permit trading, I assume the convenience yield related to the scarcity of the permits bank is not a factor affecting banking decisions of individual units. i.e. $\varpi^{*}=0$.

Combining equations (11) and (14) yields the following policy function for intertemporal emission trading:

$$
\beta E\left(P_{a 2}\right)=\frac{\sigma_{1}^{*} P_{l 1}-P_{h 1}}{\gamma\left(\delta_{h}-\sigma_{1}^{*} \delta_{l}\right)}
$$

where $\sigma_{1}^{*}=g_{h_{1}^{*}}^{\prime} / g_{l_{1}^{*}}^{\prime}$ is the ratio of the marginal productivities of high- and low-carbon fuel. ${ }^{11}$ The right hand side of Eq.(15) is the additional cost an operator has to pay in order to reduce one ton of carbon dioxide emission. It reflects both price and productivity differences between lowand high-carbon fuel. Following Montgomery (1972), emission abatement costs are defined as the difference between the unconstrained profits and the profits in which the firm adopts an emission level which is less than the unconstrained emission level. Therefore, the right hand side of Eq.(15) presents a notation for marginal abatement cost.

Eq.(15) together with Eq. (14) exhibit the spatial and temporal efficiency properties of a tradable emission permit regime: in each period, the marginal abatement costs are equalized across firms through the current allowance price (therefore the total pollution reduction cost is minimized) ${ }^{12}$; the present value of the marginal abatement costs are equalized across time periods in an expectation sense. Thus, expectations on higher future permit prices raise the current abatement level.

\footnotetext{
${ }^{11}$ The expected permit prices are positive implies $\delta_{h} / \delta_{l}>g^{\prime}{ }_{h} / g^{\prime}{ }_{l}$.

${ }^{12}$ This conclusion is based on the assumption that firms have interior solutions, i.e. both low- and high-carbon fuels are used. If firms only use one type of fuel, marginal abatement costs are not equalized between firms having interior solutions and firms having corner solutions; however, an emission trading program still yields a cost effective result.
} 
Plugging $\beta=1 /(1+r)$ into Eq.(14), we obtain Hotelling's rule under uncertainty.

$$
\frac{E\left(P_{a 2}\right)-P_{a 1}}{P_{a 1}}=r
$$

Eqs. (14) and (15) show that firms have incentives to save permits for future use (forward banking) every time they expect the discounted future permit price to be greater than the current market price; at the industry level, such forward banking will drive up the current permit prices, as well as the current marginal abatement costs, to reflect the expectation of future permit prices. Eq.(16) shows that a direct result of forward banking is to prevent the expected permit price from increasing at a rate higher than the interest rate.

\section{III (ii) Uncertainty, Banking and Emission}

Although price is given for each individual unit in the permit market, allowance price is endogenously determined by the aggregate behavior of the generating units. Previous theoretical analysis of emission permit trading reveals that when allowed to trade with one another in a competitive allowance market, units will collectively behave like a central planner who efficiently allocates emission permits to each unit in a manner that minimizes total costs (Rubin, 1996; Schennach, 2000; Feng and Zhao, 2006). This insight allows me to model the aggregate industrial behavior as a single representative unit and solve the equivalent and simpler problem without considering internal spatial trading. Assuming the representative agent uses low- and high-carbon fuel to produce electricity according to the Cobb-Douglas production function ${ }^{13}$ $g(l, h)=G l^{\alpha} h^{1-\alpha}$, where $G$ is a productivity parameter, and $0<\alpha<1$ is the share of low-carbon fuel. To avoid confusing the issues of increasing price volatility with increasing price trends, I consider electricity price $P_{e}$ evolves following a mean-preserving stochastic process with the mean equal to $\bar{P}_{e}$. Formally, I define the probability distribution function of $P_{e}$ as $f\left(\bar{P}_{e}, \theta\right)$ such that

$$
\int P_{e 2} d f(\cdot, \theta)=\bar{P}_{e} \quad \forall \theta
$$

where $\theta$ is an index of the mean-preserving spread and if $\theta^{\prime}>\theta, f(\cdot, \theta)$ second-order stochastically dominates $f\left(\cdot, \theta^{\prime}\right)$ (or $f\left(\cdot, \theta^{\prime}\right)$ is more risky than $f(\cdot, \theta)$ ). Therefore, the value of $\theta$ characterizes the level of market-wide risk. The representative firm's optimization problem in period-2 shown below is simplified by leaving out the term $x$.

$$
\begin{aligned}
& \max V=P_{e 2} g\left(l_{2}, h_{2}\right)-c\left(l_{2}, h_{2}\right) \\
& \text { s. t. } \quad B_{2}=e\left(l_{2}, h_{2}\right)=\gamma\left(\delta_{l} l_{2}+\delta_{h} h_{2}\right)
\end{aligned}
$$

There is no closed-form solution for the above optimization problem. Nonetheless, I prove analytically in Appendix A that the marginal profitability of permits $\partial V / \partial B$, or the permit price $P a$, is convex in the stochastic variable $P$. This leads to a negative relationship between ex ante emissions and the level of uncertainties about electricity prices.

\footnotetext{
${ }^{13}$ In Appendix A I extend the model to a more general CES production function and prove that the conclusions do not change.
} 
Proposition 1. Increasing uncertainty over electricity price generates lower ex ante emissions and higher banking in the following sense: For $\theta^{\prime}>\theta, B\left(P_{e}{ }^{\prime}\right)>B(\theta)$ and $e_{i}\left(\theta^{\prime}\right)<e_{i}(\theta)$, where $\theta$ is the mean-preserving spread of electricity price, $B$ is the aggregate stock of banked emission permits of the industry, and $e_{i}$ is the individual ex ante emissions.

Proof. I prove in Appendix A that the marginal profitability of permits is convex with respect to $P e$. It follows directly from Jensen's inequality that an increase in the mean preserving spread of $P_{e}$ increases the expected marginal value of permits. According to Eq.(15), in anticipation of higher expected future marginal value of permits, firms will reduce ex ante emissions by increasing the current marginal abatement costs, which leads to an increased aggregate stock of allowances at the industry level,

It is essential that the marginal value of allowances be convex in electricity prices to derive the above conclusion. This convexity reveals an asymmetric distribution of future marginal values of allowances due to output prices change. To understand the intuition, note that because the total number of allowances is fixed, and is less than the emissions expected to produce by all of the affected units, the rise of electricity prices increases the counterfactual emissions, as well as the total required pollution reduction. Since abatement costs are convex (more discussion of this property in the next section), marginal abatement cost rises with the quantity of abatement. Therefore, when electricity price increases, the marginal abatement cost increases faster then it decreases when electricity price falls. This means that the potential gain from saving an additional unit of permit is higher when electricity price increases than the potential loss when electricity price decreases. When uncertainty is more pronounced, very high and very low electricity prices become more likely, and this asymmetric relationship becomes more salient. In the presence of extreme prices, firms would have a higher incentive to save permits as the potential gain is much higher than the potential loss.

In addition, when there are multiple time periods, the convexity effect also works through firms' ability to vary the input of permits in response to the resolution of uncertainty. When there is a "bad" shock such that the stock of permits is larger than the desired stock of permits, firms can choose not to use extra permits. Thus, the marginal gain from saving a unit of permit today equals max $\left[0, \beta P_{a 2}-P_{a 1}\right]$. A "good" shock is unchecked, while a "bad" shock is bounded below. Therefore, a unit of permit is like a set of American call options on future production, which is worth more when good and bad outcomes are more extreme with the same expected mean value.

Based on a similar analysis, I show in Appendix B that the marginal value of permits is also a convex function of input costs: the prices of low- and high-carbon fuel. The intuition follows the same line: the fluctuation of input costs changes the counterfactual emission level, leading to an asymmetric probability distribution for the marginal profit of permits: negative shocks which increase the input costs will reduce the marginal value of permits less than positive shocks will increase them, Hence, in equilibrium more permits will be saved in presence of a mean preserving spread in the distribution of $P_{l}$ or $P_{h}$ which raises the expected marginal profitability of permits.

Lemma 1. The greater the uncertainty in input costs $P_{l}$ and $P_{h}$, the lower are the ex ante emissions. 
Proof. See Appendix B.

To be noticed, that assuming perfectly competitive allowance market, the above conclusions are derived regardless of firms' market position (net seller or buyer) and the initial allocation of allowances.

\section{III.(iii) Imperfect Competition and Return to Scale}

Proposition 1 and Lemma 1 are proved under the assumptions that individual firms are price-takers and production technology is linearly homogeneous. In this section, I discuss the role of perfect competition and returns to scale. I show that imperfect competition in an electricity market and decreasing returns to scale do not affect the negative relationship between uncertainty and emission. However, this negative relationship may not be robust to increasing returns to scale or imperfect competition in the permit market.

\section{A. Imperfect Electricity Market}

To isolate the impact of imperfect competition in electricity market, assume the technology is still described by a homogenous of degree one Cobb-Douglas production function: $g=G l^{\alpha} h^{1-\alpha}$. Suppose an individual firm faces an isoelastic demand curve $P_{e}=g^{(1-\varphi) / \varphi} W$, where $\varphi(\varphi \geq 1)$ is a markup coefficient with $\varphi=1$ corresponding to perfect competition. $W$ is an exogenous stochastic demand shifter that captures industry-wide shocks. Under these conditions, the value function is equal to:

$$
V=W\left(G l^{\alpha} h^{1-\alpha}\right)^{\varepsilon}-P_{l} l-P_{h} h
$$

where $\varepsilon=1 / \varphi, \varepsilon \leq 1, \varepsilon$ can be considered as the return-to-scale parameter. Appendix $\mathrm{C}$ shows that with a value function described by Eq.(20), the convexity of the marginal value of permits in output price and input costs persists. Therefore, the fact that an electricity market may not be perfectly competitive does not affect the conclusion regarding the negative relationship between uncertainty and ex ante emissions given constant returns to scale and perfect competition in permit market (as well as risk neutrality).

This result confirms the intuition of the above analysis. Recall that a crucial insight from Eq.(12) is that abatement decisions do not depend on either past or future permit stocks. This lack of "intertemporal links" holds true as long as firms are price takers in the permit market and does not depend on the elasticity of the demand curve facing individual firms in the electricity market. Therefore, an industry-wide shock will have a similar impact on abatement decisions for a competitive firm and a monopolist with constant returns to scale in the electricity market: how many permits is saved now affects profits in the future, but not the level of emissions in the future. As such, any increase in the expected marginal profitability of permits, including the one caused by an increase in market uncertainty raises the emission banking today.

One concern about above analysis is that the industry itself may face a downward-sloping demand curve even when individual firms are perfectly competitive and have constant returns to scale. When price is endogenously determined by the industry output, the amount a price can rise under good industry-wide outcomes is limited by the entry of new firms and the expansion of existing ones. If investment is irreversible, as shown by Pindyck (1993), there is no similar 
mechanism to prevent price from falling under bad demand outcomes. As a result, a meanpreserving distribution of future output prices might not be sustained. However, because fossil fuel fired peak power plants which are usually the marginal producers, can be fairly easily turned on or shut down in response to the realized market price, the possibility of an asymmetric distribution of future output price is reduced. That is the operational flexibility of peak load power plants weakened the notion of irreversibility which is instrumental in Pindyck(1993)'s analysis.

\section{B. Return to Scale}

Analysis so far assumes constant returns to scale. Relaxing this assumption, however, does not convey any additional difficulty. Eq.(20) reveals that a decrease in returns to scale operates exactly like an increase in the markup coefficient and vice versa. Therefore, conclusions of Proposition 1 and Lemma 1 fully carry over to the case of decreasing returns to scale.

The above result has an intuitive interpretation. Note that Proposition 1 and Lemma 1 hinge on the convexity of abatement costs. In principle, this convexity arises from decreasing marginal productivity of factor inputs. ${ }^{14}$ To see this, observe from Eq.(15) that marginal abatement costs is positively related to the ratio of marginal products of high- and low-carbon fuel $(\sigma)$. Because of declining marginal productivity, when producers use a greater share of low-carbon fuel to reduce emissions, $\sigma$ increases as the marginal product of low-carbon fuel declines relative to that of high-carbon fuel. Therefore, abatement costs are convex in the sense that a lower level of emissions is associated with higher abatement costs at the margin. In obtaining this result, diminishing marginal productivity is the paramount factor. Because decreasing returns to scale (so as constant returns to scale) guarantees diminishing marginal productivity (given the production function is quasi-concave) ${ }^{15}$, the negative relationship between emissions and uncertainty holds in the presence of decreasing returns to scale resulting from imperfect competition or diseconomies of scale technology, or both. Note that some cases of increasing returns may also satisfy diminishing marginal productivity. For example, suppose $\varepsilon>1$, but $0<\alpha \varepsilon<1$; the marginal productivity of $l$ decreases with the increase of $l$. However, as the returns to scale $(\varepsilon)$ becomes larger and larger, from the insights gleaned above, the inverse relationship between emissions and uncertainty would eventually lose its strength.

\section{Imperfect Permit Market}

So far we have assumed a competitive permit market, where the distribution of future allowance price is independent of an individual firm's abatement decisions. The effects of uncertainty are mediated through the equilibrium behavior of all firms and the resulting impact on prices of an allowance market. A logical question to explore is what if at least one of the units exercises market power in the allowance market. In this case, the current emission of the dominant firm would affect the expected path of the marginal value of permits. For a dominant firm, Eq.(14) becomes

$$
\frac{\partial P_{a 1}}{\partial x_{1}} x_{1}+P_{a 1}=\beta E\left[\frac{\partial P_{a 2}}{\partial x_{2}} x_{2}+P_{a 2}\right]+\varpi^{*}
$$

\footnotetext{
${ }^{14}$ Increasing marginal abatement costs or decreasing marginal productivity both imply that the firm attains a regular minimum in solving the problem.

${ }^{15}$ A formal mathematical proof is available upon request.
} 
The price function $P_{a}$ and its relationship with $P_{e}$ is intractable without further assumption of the price- or quantity-setting behavior of the dominant firm. However, as the dominant firm has the flexibility to make ex post decisions on $x_{2}$ after the demand for output market is known, the permit price $P_{a}$ becomes less convex with respect to $P_{e}$. When the ability of the dominant firm to affect the permit price increases, the firm would respond less and less to changes in the level of uncertainty. Qualitatively, I show that imperfect competition in an permit market threatens the negative relationship between price uncertainty and ex ante emissions. Further rigorous analysis is needed based upon more detailed assumptions of the market structure of the permit market and the strategic behavior of a dominant firm.

\section{Empirical Analysis}

Building on previous discussions on the dynamics of intertemporal emissions trading under uncertainty, this section empirically explores the electricity utilities' responses regarding emissions reduction to price fluctuations in the U.S. electricity markets. ${ }^{16}$ The empirical analysis is based on a panel dataset consisting of 207 Phase I coal-fired generating units from 1996 to 2004. In many ways, the U.S. $\mathrm{SO}_{2}$ allowance trading program can be compared to the emerging global carbon dioxide trading market. With 10 years of observation data and many lessons learned from the $\mathrm{SO}_{2}$ allowance market, to study $\mathrm{SO}_{2}$ trading occurred in the U.S. provides a unique opportunity to estimate the implications of different features of the global carbon dioxide trading program, including the impact of uncertainty on future development of the global carbon market.

The $\mathrm{SO}_{2}$ allowance trading program, also known as the Acid Rain Program, was established under Title IV of the Clean Air Act Amendments of 1990. By creating a national clean air market, it was a grand application of a market-based regulatory approach to achieve emission reduction goals. The basic idea behind permit trading is simple. The regulatory agency first sets a cap that limits the total $\mathrm{SO}_{2}$ emissions by more than $40 \%$ from their 1980 level (from 18.9 million tons in 1980 to 8.9 million tons by 2001). It then divides the quantity up to a number of tradable allowances and allocates them to individual firms based on their historical heat input. Each allowance grants the holder the right to emit one ton of $\mathrm{SO}_{2}$. Firms that can reduce emissions relatively cheaply may increase their profits by selling extra allowances; while those that find it expensive to reduce emissions can buy extra allowances from the market. The $\mathrm{SO}_{2}$ allowance trading program institutionalized a couple of innovations in that it not only allows unlimited trading of permits among firms, but also allows permits to be traded over time. Therefore, power producers who can reduce emissions below the number of allowances they hold may sell allowances to other firms, or bank them for future use. The only limitation the U.S. Environmental Protection Agency (EPA) imposes on the trading program is that firms cannot borrow allowances from their future allocation. At the "true-up" date (usually at the end of March of each year), each unit must submit enough allowances to cover its emissions for that year.

\footnotetext{
${ }^{16}$ I do not test the effect of coal prices uncertainties. As coal is the most abundant and affordable energy source in the United States, its price in fact remains quite stable during the sample period.
} 
Another important feature of this program is that it is a phased-in program. Phase I began in 1995 and affected 263 units at 110 mostly coal-burning (and a few oil-fired units) electric utility plants located in 21 eastern and Midwestern states. Phase I units had emissions greater than 2.5 pounds of $\mathrm{SO}_{2} / \mathrm{mmBtu}$ and a generating capacity greater than 100 megawatts (MW). Phase II began in the year 2000. It establishes a permanent cap of 8.95 million per year and affects all existing utility units with an output capacity greater than $25 \mathrm{MW}$, and all new utility units.

Figure 1 shows the annual emission cap, aggregated emissions and banked allowances from 1995 to 2004. It is apparent that the temporal dimension is a key component of this trading program. Indeed from 1995 to 1999, 11.65 million allowances had been banked, which was about $30 \%$ of the total allowances allocated during Phase I. ${ }^{17}$ These extra allowances were produced through reducing emissions in early periods below the allowable standard.

The main reason for units to bank permits is due to the phased-in aspect of the program: an allowance is perceived to be worth more in later years under the stricter cap of the Phase II. As expected, the bank accumulated during Phase I started being drawn down in year 2000, easing the transition to Phase II. However, the size of the bank generated in Phase I was unexpectedly large. Some argue that banking in this program has been excessive and was economically inefficient (Ellerman, et al., 2000; Smith, et al., 1998). In addition, the draw-down rate at the beginning of Phase I was also lower than previously expected (Ellerman and Montero, 2005). In the following, I show that part of the bank can be explained by the increased electricity price volatility during electricity market restructuring in recent years.

The implementation of the acid rain program happens to have coincided with electricity restructuring which dramatically changed the way the power industry was structured and regulated over the past decade. Before restructuring, under rate-of-return regulation, electricity price is set administratively by the regulatory agency on the basis of average production cost. After Federal Energy Regulatory Commission (FERC) issued Orders 888 and 889 in 1996, a number of auction based wholesale markets were established. In these markets firms bid to supply power and the dispatch order was set by the bids. Since electricity has been traded in these wholesale markets, uncertainty becomes a salient feature in the electricity market. In fact, electricity price volatility has exceeded that of any other commodity market in recent years.

In what follows, the model specification, data sources and empirical estimation results are discussed.

\section{IV (i) Econometric Specification}

In this section, I lay out the underlying econometric specifications for empirical tests and describe the dependent and independent variables.

\footnotetext{
${ }^{17}$ The number of banked allowances does not include allowances sold at public auction each year, nor does it include the contribution from substitution units that entered or exited the market in different years.
} 
I assume a generating unit $i$ has a production function of the following form: $g_{i}=G_{i} l^{a_{i}} h^{b_{i}}$ $\left(a_{\mathrm{i}}>0, b_{\mathrm{i}}>0\right)$; electricity price is given by $P_{e}=W g_{i}^{\varepsilon_{i}-1}$. Recall that $W$ is an exogenous process that influences the value of $P_{e}$ and $\varepsilon$ is the elasticity of demand. When the unit is a price-taker in the electricity market, there are $\varepsilon=1$ and $W=P_{e}$.

Multiplying factor inputs $l$ and $h$ on both sides of Eqs.(5) and (26) (intertemporal first-order conditions for competitive and regulated units, respectively) gives the input demand functions for $l$ and $h$ :

$$
\begin{gathered}
l_{i t}=\frac{\varepsilon_{i} \alpha_{i} W_{t} g_{i t}^{\varepsilon_{i}}}{P_{l t}+M_{l i t}\left(\beta E\left[P_{a(t+1)}-N_{i(t+1)}\right]+\varpi_{i t}\right)} \\
h_{i t}=\frac{\varepsilon_{i}\left(1-\alpha_{i}\right) W_{t} g_{i t}^{\varepsilon_{i}}}{P_{h t}+M_{h i t}\left(\beta E\left[P_{a(t+1)}-N_{i(t+1)}\right]+\varpi_{i t}\right)}
\end{gathered}
$$

where $M_{i f}=\frac{\mu_{f}}{1-R_{i t} \varphi_{i t}}(f=l, h), N_{i}=R_{i(t+1)} \tau_{i(t+1)}, R_{i}$ is a dummy variable which takes value 1 if unit $i$ is subject to ROR regulation, and 0 otherwise.

Substituting $l$ and $h$ from Eqs. (27) and (28) to the expression for $e$, we get a emission function:

$e_{i t}\left(l_{i t}, h_{i t}\right)=\mu_{l} l_{i t}+\mu_{h} h_{i t}=\frac{\varepsilon_{i} \alpha_{i} W_{t} g_{i t}^{\varepsilon_{i}}}{P_{l t}+M_{l i t}\left(\beta E\left[P_{a(t+1)}-N_{i t}\right]+\varpi_{i t}\right)}+\frac{\varepsilon_{i}\left(1-\alpha_{i}\right) W_{t} g_{i t}^{\varepsilon_{i t}}}{P_{h t}+M_{h i t}\left(\beta E\left[P_{a(t+1)}-N_{i t}\right]+\varpi_{i t}\right)}$

Dividing both sides of Eq.(29) by $g_{i t}$ and taking logs yield

$$
\ln \left(\frac{e}{g}\right)_{i t}=\ln \varepsilon_{i}+\ln P_{e i t}+\ln \left(\frac{a_{i}}{P_{l t}+M_{l i t}\left(\beta E\left[P_{a(t+1)}-N_{i}\right]+\varpi_{i}\right)}+\frac{b_{i}}{P_{h t}+M_{h i t}\left(\beta E\left[P_{a(t+1)}-N_{i}\right]+\varpi_{i}\right)}\right)
$$

Eq. (30) shows that the total emissions of unit $i$ is determined by exogenous demand shifter $W$, the output level $g_{i t}$, current and expected factor input prices $\left(P_{l}\right.$ and $\left.P_{h}\right)$, and the current and expected profit regulations $(M$ and $N)$, a series of unit specific characteristics $\left(a_{i}, b_{i}, \varepsilon_{i}\right)$, and expected future allowance prices $\mathrm{E}\left[P_{a(t+1)}\right]$, which as postulated by the theoretical analysis, is positively correlated with the variance of $P_{e i t}$. The probability of a potential stockout measured by $\varpi_{i}$ may also affect emission decisions.

Therefore, emission rates can be estimated by the following reduced form $\ln \left(\frac{e}{g}\right)_{i t}=\beta_{0}+\beta_{1} \Delta P_{e t}+\beta_{2} \ln P_{t}+\beta_{3} R_{i t}+\beta_{4} Z_{i}+\sum_{j=1}^{20} \nu S_{j}+\sum_{t=1996}^{2004} \kappa T_{t}+\alpha_{i t}+u_{i t}$

where the dependent variable is the observed annual average $\mathrm{SO}_{2}$ emission rate (in log forms) of unit $i$ in calendar year $t$. Emission rate is calculated by dividing the total annual emissions (tons) by the annual electricity output in megawatt hours (MWh). 
$\Delta P_{e i t}$ is the volatility of electricity prices. It is the key variable of interest in gauging the effect of output price uncertainty on decision makers' perception of future allowance prices and multi-period emissions distribution decisions. Observations of monthly fuel purchasing database reveal that plants frequently purchase coal from spot markets during the year. Therefore, decisions as to how much of each type of coal to buy and how many allowances to hold till later periods can be adjusted in response to the monthly electricity price fluctuations. I measure $\Delta P_{\text {eit }}$ as the standard deviation of the percentage change (between two adjacent months) of monthly average electricity price in the state where unit $i$ is located. As we tend to see higher overall underlying prices in highly volatile periods, this definition facilitates normalizations and reasonable comparison across high and low price levels. The calculation is described by Eq.(32).

$$
\Delta P_{\text {eit }}=\sqrt{\sum_{m=1}^{12}\left[\frac{P_{e i t m}}{P_{\text {eit }(m-1)}}-E\left(\frac{P_{\text {eitm }}}{P_{\text {eit }(m-1)}}\right)\right]^{2}} \times 100
$$

where $t$ indexes year and $m$ indexes month. $P_{\text {eitn }}$ is the monthly average retail electricity price to industrial customers in state $i$ during month $m$ year $t$.

The coefficient of $\Delta P_{e t}$ provides a measure of the elasticity of annual average emission rate to electricity price volatility. A negative coefficient will provide supporting evidence for the theoretical prediction in previous sections.

The above analysis implicitly assumes current price fluctuation as a proxy for expected price uncertainty in the future. One concern with this specification is whether current price uncertainty reflects plant operators' expectation of future price uncertainty at the time of making operation decisions. To evaluate the possibility that historical price uncertainty does not provide insights into expectation of future price changes, I also assume mangers perfectly predict price volatility in the future $\left(\Delta P_{e(t+1)}\right)$, and test for the response of current emission rate to future price fluctuation. This alternative specification does not change the result qualitatively.

Given input costs, an increase in electricity prices will increase the marginal value of allowances. According to Eq.(A6), the higher the marginal value of allowances, the higher the input ratio for low-sulfur coal, which implies a lower emission rate. Therefore, the coefficient associated with $P e$ is expected to be negative.

$P_{t}$ is a price vector including the price of allowances $P_{a t}$; low-sulfur coal price $P_{l t}$; highsulfur coal price $P_{h t}$, and retail electricity price to industrial customers $P_{e t}$.

Current price $P_{a t}$ is an indicator of the market's perception of allowances future prices. A higher $P_{a t}$ would reduce current emissions and the coefficient of $P_{a t}$ is likely to be negative.

The coefficient associated with low-sulfur coal price is expected to be positive, while the sign of the coefficient of high-sulfur coal price is ambiguous. Holding the output price constant, a change in input fuel prices has two substitution effects: the substitution between the two types 
of coal, and the substitution between low-sulfur coal and allowances. ${ }^{18}$ When low-sulfur coal prices increase, both substitution effects raise emission rates. However, when the high-sulfur coal price increases, the two substitution effects work in opposite ways, leaving the sign of $P_{h t}$ indeterminate.

To estimate the impact of ROR regulations on emissions behavior, I construct two dummy

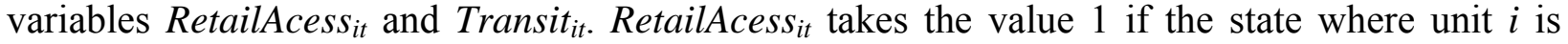
located has begun retail access to industrial customers during year $t, 0$ otherwise; Transit ${ }_{i t}$ takes the value 1 when unit $i$ is located in a state that is in a transitional period of electricity restructuring but has not yet started retail access, 0 otherwise. I define a state undergoing transition to retail competition when any one of the following two events occurs: (1) PUC issues a final order that contains a date by which all PUC-regulated utilities in the state must open their markets to retail competition; (2) the PUC has required retail restructuring filings from its regulated utilities in preparation for competition by a particular date, even if it has not yet issued a final comprehensive order. Based on previous analysis, if deregulated units have higher incentive to reduce emissions while transitional units are less motivated to bank permits, then the coefficients of RetailAcess ${ }_{i t}$ and Transit ${ }_{i t}$ would be negative and positive, respectively.

$Z_{i t}$ is a vector of unit specific characteristics that may also determine emission performances, which include:

SCRUBER $R_{i t}$, dummy constructed to be 1 if a scrubber is installed to reduce $\mathrm{SO}_{2}$ emissions. Scrubber can remove up to $90 \%$ of $\mathrm{SO}_{2}$ emitted during the production process. The coefficient associated with $S C R U B E R_{i t}$ is likely to be significantly negative.

$A G E_{i t}$, the age of the boiler installed, calculated by using the calendar year to minus the year of initial operation. Given that age and emission performance may not be in a linear relationship, I estimate the model allowing $A G E_{i t}$ to enter with a quadratic specification.

HEATRATE $_{\text {it }}$ is a measure of unit efficiency in transferring energy into electricity. It is calculated by dividing the net kilowatt hours (KWh) of power output by the Btu content ${ }^{19}$ of the fuel input. The sign of the coefficient for HEATRATE $E_{i t}$ is expected to be negative because of the inverse relationship between heat rate and production efficiency.

$C A P_{i}$ is the design capacity of the boiler expressed in megawatts (MW). The variable is included to capture possible economies or diseconomies of scale. As suggested by previous literature (Baumeister et al., 1980; Joskow and Schmalensee, 1987), the underlying thermodynamic properties of a steam cycle imply that increasing the size of the boiler should reduce the unit's heat rate, at least within some range. However, the advantage of larger size tends to deteriorate as scale becomes very large. With this a priori on the effect of boiler scale, I include the first and second order terms of $C A P_{i}$ in the regression.

\footnotetext{
${ }^{18}$ Recall in Appendix A I prove a negative relationship between fuel costs and allowance prices (Eq.[A14]). Therefore, changes in input fuel costs also changes the allowance prices.

${ }^{19}$ Btu stands for British thermal unit, a unit of energy frequently used to describe the heat value (energy content) of fuels.
} 
WORKLOAD it is the ratio between the actual operating hours during year $t$ and the maximum working hours of a year ( 8640 hours). Emission rate may also be affected by operating conditions. For example, it is generally understood that frequent ramp up and down tends to increase the level of emissions. I constructed the variable $W O R K L O A D_{i t}$ to capture the impact of different operating practices between base load and peak load plants on emissions. The coefficient of WORKLOAD $D_{i t}$ is expected to be negative.

INITIAL $L_{i t}$ is the initial allocation of allowances (tons) issued by the EPA. Although emission decisions of a price-taking unit are generally independent of its allowances endowment, INITIA $L_{i t}$ can be negatively correlated with the value of convenience yield $\left(\varpi_{i t}\right)$ when nonnegativity constraints are binding. ${ }^{20}$ However, since the non-negativity constraints are inconsequential during Phase I of the trading program, I expect estimation on $I N I T I A L_{i}$ to be positive, but the effect is likely to be tenuous.

$M U N I_{i}$ is a dummy equal to 1 when the generating unit is municipally or cooperatively owned, and 0 otherwise. I interact $M U N I_{i}$ with the measure of electricity price uncertainty $\Delta P_{\text {eit }}$. An extensive literature has discussed the relative inefficiency of publicly owned facilities. If $M U N I_{i}$ units are less cost conscious, operational activity of these units will be less responsive to output price fluctuations. Therefore, I expect coefficient of the interaction term to be positive.

Finally, I also include year and state dummies $T_{t}$ and $S_{j}$. Year dummies can capture yearspecific differences in emission performance common to all units, such as secular technology or productivity shocks. State dummies are included to control time-invariant state specific regulatory policies that may influence the cross-sectional variation in emissions. For example, many generating units were subject to sulfur restrictions contained in State Implementation Plans, which where enforced prior to the Acid Rain Program and are still in effect. Some of these local regulations are more stringent than those of the Acid Rain Program, and therefore consistently affect the emission rates of the units in those states. ${ }^{21}$

An unobservable time-invariant unit specific characteristic is represented by $\alpha_{i}$ and is assumed to affect emission performance as well. The disturbance term $\varepsilon$ is assumed to be an idiosyncratic shock to operating performance drawn from an identical and independent distribution (iid) $\varepsilon_{i t} \sim N\left(0, \sigma_{\varepsilon}^{2}\right) . \beta_{0}, \beta_{2}, \ldots, \beta_{5}, v$ and $\kappa$ are the coefficients.

As a direct analog to Eq.(31), I also test if the percentage change in the amount of allowances banked between two time periods has any bearing on output price uncertainty (the dependent variable is $\left[B_{t+1}-B_{t}\right] / B_{t}$ ). Because allowance banking is negatively related to total emissions, the coefficients of the above explanatory variables would have similar interpretations but are expected to have opposite signs.

\footnotetext{
${ }^{20}$ For example, when initial allocation increases, a potential stockout is less likely to occur and the convenience yield becomes less important.

${ }^{21}$ Specifically, states that have such regulations are Kansas, Michigan, Wisconsin, New York and New Hampshire. These states had enacted acid rain laws or taken regulatory actions to reduce $\mathrm{SO}_{2}$ emissions that were in effect by 1993 and would observe lower emission levels overall.
} 


\section{IV. (ii) Disturbance Term Structure and Alternative Specifications}

The regression model (31) is based on the assumption that units are price-takers in the allowance market. One potential concern is that the equilibrium allowance price could be endogenously determined by units that abuse market power. Emission price endogeneity may be particularly relevant in the first couple of years of the trading program when the market was not liquid enough and the price determination process might have involved significant interplay of supply and demand between only a few companies.

To test for the possibility of allowance prices endogeneity, I use the annual average natural gas wellhead price ${ }^{22}$ as an instrument for the allowance price. Natural gas and coal are competing fuels for electricity generation. Fluctuations in natural gas prices have the potential to influence the market share of coal-fired generation, which is a major driving factor of allowance prices. However, since natural gas prices are generally determined by weather conditions (hot summer days, cold winter days), the prices of substituting fuel (oil and gasoline), and economic activities, may not be directly correlated with individual units' emission rates. As robustness check, I dropped potential noisy observations for the early years (1996 and 1997) and compare the results of this reduced sample estimation with that of the full sample.

In addition to allowances price endogeneity, the endogeneity of low- and high-sulfur coal costs may arise as an issue if coal prices are determined by the demand for coal. A more likely situation is that because coal is a differentiated product in terms of both quality (sulfur content, Btu content, moisture content) ${ }^{23}$ and location, coal suppliers (producers and carriers) may have great latitude in formulating prices, while electric generating units are price-takers in coal markets,. When pricing decisions are correlated with unobservable factors affecting a unit's choice for coal and its emission performance, estimations ignoring this correlation would be biased.

Given the potential endogeneity of coal prices, following Ellerman and Montero (1998), I use the distance from a unit to the Power River Basin (PRB) in Wyoming and Montana as a proxy for the prices of the low-sulfur coal available to the units. ${ }^{24}$ The rationale for using this variable is that PRB produces most of low-sulfur coal in the U.S. with the cheapest coal-mine prices, while transportation costs factor importantly into the delivered price of coal. ${ }^{25} \mathrm{~A}$ unit's location in relation to PRB coal will to some extent reflect the actual cost of low-sulfur coal or other competing coals. However, as Ellerman and Montero (1998) and Montero (1999) point out, the distance to the PRB coal does not affect low-sulfur coal price uniformly. In particular, lowsulfur coal from central Appalachia becomes more competitive for units 1000 miles away from Wyoming. To reflect this nonlinear relationship, I included a third degree polynomial to control for the distance. It is expected that low-sulfur coal price will first increase with the increase of

\footnotetext{
${ }^{22}$ Wellhead price is the value at the mouth of the well. In general, the wellhead price is considered to be the sales price obtainable from a third party in an arm's length transaction.

${ }^{23}$ Some fuel contracts specify more than a dozen attributes of coal qualities.

${ }^{24}$ Ideally, to control for the potential fuel price endogeneity, I would estimate hedonic price functions for fuel. However, it is not possible to identify all of the relevant fuel attributes that might be important in determining fuel prices, such as the fuel grandability, fuel size or the chemical content of the fuel.

${ }^{25}$ In fact, for some western coal hauls, transportation costs account for up to $75 \%$ of delivered fuel costs. (EIA, 1995),
} 
distance to PRB coal and then decrease as more alternative low-sulfur coals become available. The distance variable and low-sulfur coal price premium are both included as proxies for lowand high-sulfur coal prices.

Specifications in (31) establish correlations between state restructuring activity and emission level. Previous studies (Joskow, 1997; White, 1996) suggest that a major motivation for electricity restructuring was to remedy the problem of high electricity prices in the Northeast and California. Under ROR regulation, PUCs set the price of electricity based on the determination of recoverable costs. If dirty and less efficient coal power plants in the Northeast contributed to regional high electricity prices by passing on high environmental control costs to consumers, which in turn induced restructuring, regulatory variables RetailAccess and Transit may be endogenous to emission rates. A fixed effects model would be able to address the endogeneity concern. A fixed effects model levels out the inherent variations in unit operation that potentially correlated with the emission rates, and therefore we can still test how changes in price volatilities changes emission rates for the same unit across time periods. ${ }^{26}$

Finally, results could be affected by sample attrition issues due to plants being removed from the reporting database. In fact, starting in 1998, many plants were divested to non-utilities and dropped from the sample because cost data of nonutility generating facilities are not reported to the public. If divestiture decisions were driven by unobservable unit specific characteristics, which make them systematically different from non-diverstitured plants, for example, if divestitured plants tend to be more competitive and produce fewer emissions given a level of output, then the estimation would also be biased. To assess if divestiture creates an attrition bias, I obtain the estimation results from a balanced sub-panel composed of units that remain in the database through 2004. The sample selection problem would be most severe in this specification if observations were not missing at random.

The stochastic disturbances in the estimating equations are assumed to be correlated across observations. ${ }^{27}$ To obtain robust standard errors, I adjusted standard errors for clustering by unit in the following estimations.

\section{IV. (iii) Data}

I began construction of the dataset with all privately and public owned Phase I coal-fired generating units. For these units, I constructed a panel dataset beginning in 1996, the first year for which coal prices are available, and ending in 2004, the last year for which the allowances trading data were updated. The data are collected and merged from several data sources to obtain information concerning annual aggregate productions, quality and quantity of coal used, and SO2

\footnotetext{
${ }^{26}$ Fixed effects model is not sufficient to avoid endogeneity bias if restructuring policies are adopted in response to the trend in operating performance. Given that restructuring decisions were generally made before 2000, I conducted reduced sample estimation based on observations from 2000 to 2004. This alternative specification does not change the magnitude and significance of the results from the full sample; therefore, suggest that the endogeneity of regulatory statuses variables may not be a particular concern.

${ }^{27}$ Estimated average first-order autocorrelation coefficients indicate $u_{i t}$ is likely to be serially correlated. In the emission rate equation, the coefficient is 0.26 in the fixed effects model; in the percentage change of annually banked allowance model, the coefficient is -0.38 in the fixed effects model. The likelihood ratio test also shows evidence of cross-sectional heteroskedasticity.
} 
emitted during the production process, allowances allocated and banked, electricity prices, input fuel prices, regulatory statuses and a variety of unit-level characteristics. This merging process reduced the sample size, both because of differences in units covered among datasets and because divestitures removed the plants from the reporting database after 1998. The final dataset is unbalanced and is composed of 207 Phase I coal-fired generating units. All prices are adjusted to real terms using a 5\% discount rate and presented in 1996 dollars. Details of the dataset collection and construction procedures are described in Appendix D.

Table II presents summary statistics. Table III gives the unit-year observations on the number of units that have been affected by electricity restructuring, installed scrubbers, experienced fuel switching, or avoided fuel blending. Table III shows that there are rich variations in fuel inputs and regulatory statuses of the units in both longitudinal and crosssectional dimensions. In contrast, the number of scrubbers installed remains almost constant (except for sample attrition that reduces the number) suggesting that changes in emission rates may not be initiated by the installation of scrubbers.

I also calculate the Herfindahl-Hirschman Index (HHI) to measure market concentration in the allowance trading market each year from 1995 to 2004. Generally, the largest seller or buyer (at the plant level) of allowances has a market share no larger than $3 \%$ and the HHI is consistently lower than 100 across years, which suggests that market power may not be a significant issue in the allowance market.

\section{IV. (iv) Estimation Results}

This section presents estimation results for model (31). I also estimate a number of alternative specifications to investigate potential endogeneity biases and found that they do not affect the results.

Table IV reports results from estimating equation (31) using the log of units' annual average emission rate as the dependent variable (In[EmissionRate]). Column (1) and (2) report results from unit fixed and random effects models. A Hausman test suggests that the unobservable error term $\alpha_{i}$ is correlated with at least one of the explanatory variables. Therefore, only the fixed effects model yields a consistent and unbiased estimation. Nonetheless, the estimated coefficients of variable $\Delta P_{e t}$ are similar and are both negative and statistically significant from zero. This result is consistent with the theoretical prediction of a negative correlation between emission rate and electricity price volatility. In particular, based on the fixed effects specification, a one percent increase in price volatility is associated with a decrease in unit's annual average emission rate by $0.88 \%$. This means a one-standard deviation increase in electricity price volatility would induce a sample "average" unit to reduce annual aggregate emissions by 423 tons. With a 95 percent confidence interval, the emission reduction would be anywhere from 383 to 827 tons.

Estimations on the other explanatory variables are generally consistent with prior expectations. The estimates on SCRUBBER show that the installation of a scrubber would on average markedly reduce emission rates by $91 \%$. Publicly owned units are less responsive to electricity price volatilities: the emission rate elasticity of a municipal or cooperatively owned 
unit is one-third lower than that of an investor owned unit. Estimated coefficient on HEATRATE shows that inefficient production is associated with higher pollution emissions. Higher allowance prices, as well as higher electricity prices induce lower emission rates; in contrast, there is a positive relationship between low- and high-sulfur coal prices and emission rates. However, coefficients of these price variables are not statistically significant from zero in the fixed effects model. AGE does not have a significant impact on emission rates. The reason could be that HEATRATE depletes all explaining power regarding the effect of production efficiency on emission performance. Finally, note that different regulatory statuses do not have significant impact on emission rates, although coefficients of both variables RetailAccess and Transit have the expected sign.

Column (3) of Table IV presents IV/2SLS estimation results using natural gas wellhead price as an instrument for $\mathrm{SO}_{2}$ allowance price. The first stage $F$-statistics is 22, suggesting that natural gas price is not a weak instrument. I compare IV/2SLS estimates with those of the fixed effects model. A Hausman test suggests that allowing $\mathrm{SO}_{2}$ allowance price to enter as an independent variable yields almost the same estimates as those based on instrumentation. The statistics is $\chi^{2}(19)=24.50$ and the $P$-value is 0.1775 . Therefore, the endogeneity of allowance price does not seem to be a particular concern. Indeed, using IV/2SLS estimation does not affect the estimated coefficient of electricity price volatility in either magnitude or statistic significance.

Column (4) of Table IV reports reduced sample estimation. Potentially noisy observations in the early period of the trading program are dropped. The 2004 data are also excluded from the analysis. In 2004, the spot price of $\mathrm{SO}_{2}$ allowances, which had been steady at about $\$ 200 /$ ton, were increased by three-fold after the EPA proposed the Clean Air Interstate Rule that will effectively lower the $\mathrm{SO}_{2}$ emission cap by two-thirds beginning in 2010. Although the price response to upcoming stricter limits on emissions provides further evidence on units' intertemporal optimization behavior, it may swamp the effect of price volatility on emissions trading. Therefore, regression was restricted to the years 1998 through 2003. This alternative specification does not qualitatively change coefficient estimation for price volatility although it is slightly larger than the one received from the full sample year estimation.

To assess if divestiture creates attrition bias, I obtain the estimation from a balanced subpanel composed of units that remain in the database through 2004. The sample selection problem would be most severe in this specification if observations were not missing at random. The results are given in column (5) of Table IV. The estimated coefficient on $\Delta P_{e}$ is quite similar to those from pervious models, indicating that divestitured units may not be systematically different from other units regarding the response in emission decisions to price volatility.

As another robustness check, I collect data on the emission rates of Phase I affected units in 1993 as a counterfactual to examine if the change in emission rates can be explained by change in electricity price volatility. Specifically, I estimate a fixed effects model described by Eq.(33). With no changes in price volatility, coefficient of price volatility is expected to be zero. About 90 units were not in operation in 1993. Therefore, the sample size is reduced to 118 units in this regression. The estimated coefficients are reported in column (6) of Table IV. The results are fully consistent with expectations. The coefficient of price volatility is statistically significant and is negatively correlated with the emission rate change. To be noted, the coefficient 
associated with SCRUBBER is much smaller compared to those from other models. This result again confirms the fact that because most of the scrubbers were installed before the enactment of the Acid Rain Program, the installation of scrubbers is not a major factor that drives the decreasing trend in emission rates.

$$
\begin{aligned}
& E R T_{i t}-E R T_{93 i}=\beta_{0}+\beta_{0}{ }^{\prime} R T E_{93 i}+\beta_{1} \ln \Delta P_{e i t} R T E_{93 i}+\beta_{2} P_{e i t} \cdot R T E_{93 i}+\beta_{3} R_{i t} \cdot R T E_{93 i}+\beta_{4} Z_{i t} \cdot R T E_{93 i} \\
& +\sum_{j=1}^{18} v S_{j}+\sum_{t=1996}^{2004} \kappa T_{t}+\alpha_{i t}+u_{i t}
\end{aligned}
$$

Overall, results from alternative specifications closely resemble the basic fixed effects estimation in column (1). In all cases, the relationship between electricity price volatility and emission rate, shown in the first row of Table IV, is statistically negative with an estimated elasticity around $0.8 \%-0.9 \%$. All four sets of alternative specifications produced qualitatively similar results on coefficients of other independent variables as well.

The columns in Table V are structured in a manner similar to those in Table IV. Specifically, the first two columns report the results from the fixed effects and random effects models. A Hausman test does not reject the null hypothesis that the cross-sectional error term $u_{i t}$ is not correlated with the other independent variables. Therefore, both the fixed and random effects models provide consistent estimations. Nonetheless, in the following, I still report results from fixed effects estimation, which are not systematically different from those of a random effects model. Table $\mathrm{V}$ shows that the coefficients on price volatility are positive and statistically distinguishable from zero. Alternative specifications have almost no effect on the estimation results on the coefficient of price volatility, except for specification in column (5) which corresponds to estimations of the balanced panel dataset. The lower estimated coefficient of $\Delta P_{e}$ in column (5) indicates that there could be differences in the elasticity of allowance savings between divestitured and non-diversitured units. Recall that the size of a unit's allowance bank $\left(B i_{(t+1)}\right)$ is determined by both levels of emissions $\left(e_{i t}\right)$ and trading with other units $\left(x_{i t}\right)$. Given that the emission elasticities of these two types of units are similar as suggested by Table IV, the difference in estimated coefficients of $\Delta P_{e}$ could be explained by different trading strategies: diverstitured units could be more aggressive in purchasing allowances in response to higher electricity price fluctuations.

Based on column (2) in Table V, a one percent increase in electricity price volatility is on average associated with an increase of $2.46 \%$ in the size of the allowance bank. This implies that when electricity price volatility increases by a one-standard deviation, a sample "average" unit will carry an additional 1027 tons of allowances forward to the next period. The $95 \%$ confidence interval is between 137 to 1918 tons. Coefficients of other independent variables generally remain consistent with prior expectations.

Considering the potential endogeneity of delivered coal prices, I control for units' location in relation to PRB coal (miles) and the observed price difference between low- and high-sulfur coal prices. Table VI reports estimation results for emission rate (columns [1] and [2]) and the percentage change in annual allowance stocks (columns [3] and [4]) based on these specifications. Regressions (2) and (4) reported in Table VI also instrument $\mathrm{SO}_{2}$ allowance prices 
by natural-gas wellhead price. Coefficients of electricity price volatility are consistent with previous estimations in all models. In addition, the three distance coefficients are individually statistically significant. The U-shaped profile derived from the distance coefficients echoes the results from Ellerman and Montero (1998), suggesting that low-sulfur coal prices fall for units 900 miles away from a PRB coal mine.

I use actual price volatility level in 1992 as those that would have prevailed in the absence of electricity restructuring and compute the corresponding emission rate on the basis of results of model (1) in Table IV. With expected counterfactual price volatility, extra allowances - the difference between counterfactual emissions and actual emissions is about $11 \%$ of the total banked allowances. Similar values are obtained using coefficients from the models (2) - (8). Following the same exercise but using the average price volatility level during the prerestructuring period (1990-1995) as the counterfactual, the increased price volatility can explain about $8 \%$ of the total allowances banked by the sample units during Phase I of the acid rain program. Similarly, I calculate the counterfactual allowance stock based on estimations gleaned from model (2) of Table V. I found increased price volatility can explain $6 \%$ of the total banking. Using coefficient estimates from models (1) - (8), I found this number will be between $7 \%$ to $10 \%$.

\section{Welfare Analysis and Policy Implications}

To gain further insight into the effects of uncertainty on the time-series behavior of banking and emission, I numerically simulate the banking pattern, emission stream and permit price path over time resulting from different price volatilities and contrast them to the results that would occur in the absence of uncertainty. Given different social damage functions, I calculate the potential welfare impact of increased price volatility and discuss the policy implications.

\section{V (i) Simulation of Emission Trading under Different Price Volatilities}

In the following, I analyze emission banking from the perspective of the polluting industry and ignore internal spatial trading within the industry. A representative agent is assumed to maximize the present discounted value of profit over a planning horizon spanning from 1995 to 2020 based on a production function $g=G\left(l^{a} h^{b}\right)^{\varepsilon}$. The permit market is assumed to be perfectly competitive. The optimization problem is described by Eqs.(17) and (18) in section III. In addition, I assume the electricity price $P_{e t}$ evolves following a mean-preserving stochastic process:

$$
P_{e t}= \begin{cases}\bar{P}_{e}+\theta & \text { with prob } q \\ \bar{P}_{e} & \text { with prob } 1-2 q \\ \bar{P}_{e}-\theta & \text { with prob } q\end{cases}
$$

where $\bar{P}_{e}$ is the expected mean of the electricity price; $q$ denotes the probability that a price moves up or down by $\theta$. Both $q$ and $\theta$ measure the magnitude of uncertainty. To be consistent with previous analyses, I vary the value of $\theta$ from 0 to 1 , while keeping $q$ constant at 0.3 . To 
focus attention on the impact of uncertainty, I have chosen the realized electricity price in each period to be the same at $\bar{P}_{e}$. Annual initial allocation is 7 million tons in the first five years and is permanently capped at 3.5 million tons from the year 2000. Production parameters are chosen with the following values: $\mathrm{G}=55, \mathrm{a}=0.6, \varepsilon=0.9 .{ }^{28}$ Discount ratio $\beta$ is assumed to be 0.95 . Values of the other parameters are chosen as around the sample mean of the empirical data: $\bar{P}_{e}=$ 4.8 cents $/ \mathrm{KWh}, u_{l}=1.64 \mathrm{lb} / \mathrm{mmBTU}, u_{h}=4.41 \mathrm{lb} / \mathrm{mmBTU}, P_{l}=120$ cents $/ \mathrm{mmBTU}, P_{h}=100$ cents/mmBTU. ${ }^{29}$ Permit price is endogenously determined by the operational behavior of the agent according to Eq.(A8). The process of simulation is discussed in detail in Appendix E.

Numerical analysis produces robust patterns in the response of banking and emission to the increase in output price uncertainty. Figure II depicts the total amount of banked emission permits as a function of time. The dashed line corresponds to a scenario in which the price spread $\theta=0.2$ and the emission cap remain constant at 7 million tons across all periods. The shaded, fuzzy line tracks the actual allowance storage through 2004. All the other lines indicate a twostage schedule of declining emission standards (total emissions are capped at 7 million tons from 1995 to 1999 and at 3.5 million tons after year 2000) with different assumptions about price volatility $(\theta=0,0.2,0.4,0.6,0.8$, and 1$)$.

Comparing the dashed line with the other solid lines, it is apparent that when price volatility is low, tightening environmental standards provide a major incentive for producers to reduce emissions below the standards in the early years in order to accumulate credits that can be used when standards are more severe. When price volatility becomes significant ( $\theta$ increases), the asymmetric impact of uncertainty plays a more important role in determining the optimal size of bank. As anticipated, a price spread of $\theta=1$ generates the largest number of banked permits during Phase I and a zero price volatility generates the fewest. Uncertainty also affects the draw down rate of the bank. When there is no uncertainty $(\theta=0)$, the bank is depleted by the year 2008. When $\theta=1$, the banking period is remarkably extended: the bank continues to grow until 2011.

Of particular interest to the environmental authority is the effect of uncertainty on the emission stream. The annual emissions flows and the cumulative emissions in each year under different scenarios of price volatility are plotted in Figures III and IV. As noted, the emission stream associated with different price volatilities deviate substantially in the beginning and terminal periods. When prices are volatile, it is optimal to emit less in early periods and more in later periods. When these uncertainties are high enough, excessive emissions are observed towards the end.

\footnotetext{
${ }^{28}$ Ideally, I would estimate the production functions based on actual data. However, besides observing purchasing choice over low- and high-sulfur coal, there are no data on actual inputs of low- and high-sulfur coal. Production factor $G$ is chosen to be large enough so that the emission standard imposes a binding constraint on the production decision. As a sensitivity analysis, I analyze the change in $G$ on the results and find it does not change the qualitative pattern of the results.

${ }^{29}$ The price premium of low-sulfur coal, considering the coal blending adjustment cost, is chosen at 20 cents/mmBTU. I examine the importance of the value on the results in the sensitivity analysis.
} 
Also noted from Figures III and IV is that the size of early emission reductions is significant. Based on the numerical analysis, when $\theta=1$, producers would have reduced emissions by $48 \%$ more than when $\theta=0$ during the first 5 years of the program; with $\theta=0.2$ or 0.4 , early emission reductions are at the level of $5 \%$ and $14 \%$, respectively, which are in the same order of magnitude as the elasticity estimated in previous empirical analysis.

Figure $\mathrm{V}$ contains the present value permit price path under different price uncertainties. Permit price equals the marginal abatement cost. Therefore, Figure V corresponds to Figure III in the sense that the higher the emission level, the lower the permit price. For the high variance cases, permit prices are extremely high initially and plummet at the end. It is worth mentioning that the expected price differs from the realized price. Producers bank emission credits so as to equilibrate expected present value price across compliance periods. However, when uncertainty is extremely high, banking does little to smooth the actual price series.

The simulation model assumes specific parameter values for the production function and input and output prices. To test the sensitivity of results to these assumptions, a number of simulations were run with different values for $q, G, a, b, P_{l}$, and $P_{h}$. Simulation results on total banked permits under different scenarios are shown in Table VII. The results indicate that the qualitative conclusions do not hinge on the specific parameter values chosen. In addition, as shown in the first two rows of Table VII, emission banking is much larger when the probability of price movement, $q$, increases from 0.3 to 0.4 , confirming the relationship between uncertainty and emission banking from another perspective.

\section{V.(II) Welfare Analysis}

From the standpoint of economic efficiency, uncertainty shifts emission abatement to the earlier periods, therefore raising abatement costs because of the discounting effect. Assume $\beta=0.95$, when $\theta$ increases from 0 to 1 , the sum of the discounted net payoff is reduced by $9 \%$; when $\beta=0.85$, this number reaches to $20 \%$. Furthermore, high initial compliance costs generated by high uncertainty would deter new entrants and have a negative impact on the development of competitive output markets and the emerging environmental markets. Although it is generally believed that intertemporal trading creates compliance flexibility that reduces abatement costs and increase efficiency, uncertainty may dampen the cost saving properties of banking.

In addition to cost considerations, depending on the nature of the pollutants, early abatement also has different important environmental implications. If the pollutants, such as greenhouse gases, create stock damage, voluntary early reduction would yield significant environmental benefits. However, in a finite planning horizon, early abatement increases the degree to which firms will concentrate emissions to in later time periods and raise the potential of emission spikes. If the pollutants create flow damages and if the damage function is convex, emission spikes can impose increased health hazards or even trigger the threshold effect. Emission spikes could also be associated with periods of market structure change. I simulate an exemplary situation in which the price spread remains at $\theta=0.4$ through year 2002 and declines to 0.2 permanently. As shown in Figure VI, a sharp emission spike occurs one year before the expected decline in price volatility. 


\section{V.(iii) Policy Implications}

It is generally concluded that uncertainty about the cost of controlling carbon dioxide emissions make price instruments preferable to quantity instruments because the cost of limiting one ton of emissions is expected to rise as the abatement increases, while the expected benefit of each ton of carbon reduced is roughly constant because climate change is driven by stock effects rather than flow effects.(Hoel and Karp, 2001; Pizer, 2002). ${ }^{30}$ However, for a multi-period emission control, when marginal abatement costs are also uncertain for regulated sources, a tradable quota system that allows banking creates incentive for early abatement and generates substantial higher environmental benefits than a tax schedule. In addition, since the initial caps on carbon emissions are likely to be relatively undemanding, the expectation of later, more stringent caps will tend to produce even higher reduction in initial years even when the cap is non-binding. ${ }^{31}$

On the other hand, when the marginal benefits of abatement are steeper compared with the marginal costs, a quantity instrument without restrictions on the temporal transfer of emissions, may not necessarily be preferable to a price regulation. This is because a quota system exposes firms to volatile market prices, which encourages reallocation of emissions in response to observed uncertainty. When marginal damaging effects increase rapidly along with the increase of emission flows, a price instrument would be advisable to directly control the marginal social cost. Another potential solution is to employ a hybrid approach that combines a tradable quota system with some safety measures, such as restricting the intertemporal trading ratio and/or applying discounting to banked permits. The government may also consider incorporating multiple polluting industries into a national trading program so that uncertainties facing one industry can be diversified, and the importance of building up a bank to buffer unexpected price strike may be reduced.

\section{Summary and Conclusions}

In this paper, I study the theory and empirical behavior of intertemporal emission trading under uncertainty, and its implications for policy instrument choice and banking regime design. The theoretical analysis suggests a positive relationship between industry-wide uncertainty and emission banking. In an intertemporal emission trading system, increased output or input price uncertainty induces larger emission reductions and higher allowance prices. Empirical analysis based on data from the U.S. $\mathrm{SO}_{2}$ allowance market provides consistent time-series evidence. The results suggest that increased price volatility induced by electricity market restructuring could have contributed to $8-11 \%$ of the extra emission reductions during Phase I of the trading program. Numerical simulations yield similar elasticity estimates.

\footnotetext{
${ }^{30}$ The conclusion follows from Weitzman (1974) that when the slope of the marginal cost function is greater than the slope of the marginal abatement function, price instruments are preferable to quantity instruments because they are much more likely to minimize the adverse consequences of choosing the wrong level of control.

${ }^{31}$ Currently, the transfer of unused allowances from the period $2005-2007$ to the first commitment period under the Kyoto Protocol, i.e. 2008-2012, is not allowed under an EU-wide ban on banking, which from an environmental point of view, seems to be a troubling decision.
} 
Uncertainty affects the pattern of emission levels and abatement costs over time. Its impact on both economic efficiency and environmental outcomes could be sizable. I estimate and compare the welfare effects under different output price volatility and provide relevant policy recommendations.

The future work will be focused on extending the model to reflect other sources of uncertainty existing in the real world, such as uncertainties over emission cap and interest rate. For example, emission cap can be endogenously determined by the size of the global carbon market, i.e. the number of participating countries; Interest rate that reflects countries macroeconomic policy may also have important implications for the optimal emission decisions. 


\section{References}

Arimura, T.H., 2002, An Empirical Study of the SO2 Allowance Market: Effects of PUC Regulations, Journal of Environmental Economics and Management, 44, 271-289.

Baumeister et al

Carlson, C. Burtraw, D. Cropper, M. and Palmer, K.L., 2000, Sulfur Dioxide Control by Electric Utilities: What are the Gains from Trade? Journal of Political Economy, V.(108): 6: 1292 - 1326

Caballero, R. J. 1991, On the Sign of the Investment-Uncertainty Relationship, American Economic Review, V.81(1): 279-288

Christensen L.R. and Greene, W. H., 1976, Economies of Scale in Electric Power Generation, Journal of Political Economy, V.84 (4): 655 - 676

Coggins, J. and Smith, V. 1993, Some welfare effects of emission allowance trading in a twiceregulated industry, Journal of Environmental Economics and Management, 25, 275-297

Cropper, M. and Oates, W.1992, Environmental Econocmis: A Survey, Journal of Economics Literature, 30, 675-740

Cronshaw, M. and Kruse, J. B. (1996), Regulated Firms in Pollution Permit Markets with Banking, Journal of Regulatory Economics, 9, pp. 179-189

Ellerman A., H.D. Jacoby and A. Decaus, 1998, The Effects on Developing Countries of the Kyoto Protocol and $\mathrm{CO}_{2}$ Emissions Trading, Joint Program on the science and policy of global change Report No. 41, MIT, Cambridge.

Ellerman, A. D. and Montero, J.P. (1998), The Declining Trend in Sulfur Dioxide Emissions: Implications for Allowance Prices." Journal of Environmental Economics and Management, 36(1): $26-45$

EMF Report 17, 2001, Prices and Emissions in a restructured electricity market Vol I., Standford University, 2001

Energy Information Administration, 1994, Electric Utility Phase I Acid Rain Compliance Strategies for the Clean Air Act Amendments of 1990, DOE/EIA-0582, Washington, DC.

Energy Information Administration, 1995, Energy Policy Act Transportation Rate Study: Interim Report on Coal Transportation, DOE/EIA-0597, Washington, DC.

Feng, H. and Zhao, J., 2006, Alternative intertemporal permit trading regimes with stochastic abatement costs, Resources and Energy Economics, 28, 24-40

Gollop, F.M. and Z.Roberts, M.J., Environmental Regulations and Productivity Growth: The Case of Fossil-Fueled Electric Power Generation., Journal of Political Economy, 91: 654-674 
Hahn, R. W., 1984, Market Power and Transferable Property Rights, Quarterly Journal of Economics, 99 (4): $753-765$

Hoel, M. and Karp, L. (2001), Taxes and Quotas for a Stock Pollutant with Multiplicative Uncertainty, Journal of Public Economics, 82, pp. 91-114

Holland, S.P. and Mansur, E.T., 2004, Is Real-time Pricing Green? The Environmental Impacts of Electricity Demand Variance, Working Paper, CSEM WP 136, University of California Energy Institute

IEA Fuel Research, 1993, Fuel Specifications - Impact on Power Station Performance, IEACR/52, London, England

Intergovernmental Panel on Climate Change (IPCC), Climate Change 1995, Contribution of Working Group III to the Second Assessment Report of the Intergovernmental Panel Change. In J. Bruce, H.P. Lee, and E.F. Haites, eds. Cambridge University Press, Cambridge, MA, 1996

Joskow, P.L. 1997, "Restructuring, Competition and Regulatory Reform in the U.S. Electricity Sector." The Journal of Economic Perspectives, 11(3), pp. 119-38.

Kling, C. and Rubin, J., 1997, Bankable Permits for the control of environmental pollution, Journal of Public Economics, 64, pp. 101-115

Leiby, P. and Rubin, J. (2001). "Intertemporal Permit Trading for the Control of Greenhouse Gas Emissions.” Environmental \& Resource Economics, 19(3), pp. 229-256

Lecocq, F. and Crassous, R., 2003, "International Climate Regime beyond 2012 - Are Quota Allocation Rules Robust to Uncertainty?", The World Bank Policy Research Working Paper 3000

Maeda, A. (2004), "Impact of Banking and Forward Contracts on Tradable Permit Markets." Environmental Economics and Policy Studies, 6(2), pp. 81-102

Montero, J. P. 1999, Voluntary Compliance with Market-Based Environmental Policy: Evidence from the U.S. Acid Rain Program, Journal of Political Economy, V.107(5), pp. 998-1033.

Montgomery,W.D., 1972, Markets in licenses and efficient pollution control programs, American Economic Review, 79, pp. 1233-1242

Palmer and Burtraw, 2006, The Environmental Impacts of Electricity Restructuring: Looking Back and Looking Forward, Environment \& Energy Law \& Policy Journal, forthcoming

Pizer, W. A. (1997), Combining Price and Quantity Controls to Mitigate Global Climate Change, Journal of Public Economics, 85, pp. 409-434. 
Rubin, J.,1996, A model of intertemporal emission trading, banking and borrowing, Journal of Environmental Economics and Management, 31,2 69-286

Leiby, P. and Rubin, J. 2001, Intertermporal permit trading for the control of greenhouse gas emissions, Environmental and Resource Economics, 19,229-256

Maeda, A. 2004, Impact of Banking and Forward Contracts on Tradable Permit Markets. Environmental Economics and Policy Studies, 6(2), pp. 81-102

Mansur, E.T., 2005, Environmental Regulation in Oligopoly Markets: A study of electricity restructuring, Working Paper, Yale University

Michael, R. and Stiglitz, J.E. 1970, Increasing Risk I: A Definition, Journal of Economic Theory, $2,225-243$

Schennach, S.M.2000,The Economics of Pollution Permit Banking in the Context of Title IV of the 1990 Clean Air Act Amendments, Journal of Environmental Economics and Management 40, $189-210$.

Sedjo, R. A. and Marland G. 2003. Inter-trading permanent emissions credits and rented temporary carbon emissions offsets: some issues and alternatives, Climate Policy, 3(4), p.p. 435444

Stevens, B. and Rose, A. 2002, A Dynamic Analysis of the Marketable Permits Approach to Global Warming Policy: A Comparison of Spatial and Temporal Flexibility. Journal of Environmental Economics and Management, 44(1), p.p. 45-69

Stranlund, J.K. Costello, C., et al. 2005, Enforcing Emissions Trading when Emissions Permits are Bankable, Journal of Regulatory Economics, 28(2), p.p. 181-204.

Tietenberg, T.H., 1985, Emissions trading: an exercise in reforming pollution policy, Resources for the future, Washington D.C.

Van Steenberghe, V. 2005, Carbon Dioxide Abatement Costs and Permit Price: Exploring the Impact of Banking and the Role of Future Commitments, Environmental Economics and Policy Studies, 7(2), p.p. 75-107

Weitzman, M. (1974), Prices vs. Quantities, Review of Economic Studies, 41: 447-491

White, M. "Power Struggles: Explaining deregulatory reforms in electricity markets. Brooking Papers on Economic Activity: Microeconomics. pp.201-250.

Wirl, F.(2006), Consequences of irreversibilties on optimal intertemporal CO2 emission policies under uncertainty." Resource and Energy Economics, 28(2), pp. 105-123 
Yates, A. J. and Cronshaw, M. B. 2001, Pollution Permit Markets with Intertemporal Trading and Asymmetric Information, Journal of Environmental Economics and Management, 42(1), p.p. 104-118 


\section{Appendix A}

\section{PROOF:}

The Marginal Value of Allowances is Convex in the Electricity Price

\section{(A) Cobb-Douglas Production Function}

Rewrite the optimization problem for a representative firm in the industry:

$$
\max \left[P_{e} g(l, h)-c(l, h)\right]
$$

s.t.

$$
B_{2}=e(l, h)=\gamma\left(\delta_{l} l+\delta_{h} h\right)=\mu_{l} l+\mu_{h} h
$$

where $g(l, h)=G l^{\alpha} h^{1-\alpha}, c(l, h)=P_{l} l+P_{h} h ; B_{2}$ is the total available emission allowances in the terminal period.

Define the Lagrangian expression:

$$
L=P_{e} g(l, h)-c(l, h)+\lambda\left(B-\mu_{l} l-\mu_{h} h\right)
$$

The necessary first-order conditions determining a maximum at $(\hat{l}, \hat{h}, \hat{\lambda})$ are

$$
\begin{aligned}
& \partial L / \partial B=\hat{\lambda} \\
& P_{e} G \alpha \hat{l}^{\alpha-1} \widehat{h}^{1-\alpha}-P_{l}-\hat{\lambda} \mu_{l}=0 \\
& P_{e} G(1-\alpha) \widehat{l}^{\alpha} \widehat{h}^{-\alpha}-P_{h}-\hat{\lambda} \mu_{h}=0
\end{aligned}
$$

Cross-dividing (A3) and (A4) results in:

$$
\frac{P_{l}+\hat{\lambda} \mu_{l}}{P_{h}+\hat{\lambda} \mu_{h}}=\frac{\alpha}{1-\alpha} \frac{\hat{h}}{\hat{l}}
$$

The expression on the right of (A5) is the marginal rate of technical substation (MRTS) between the two types of fuel. Eq.(A5) says that at the optimum the MRTS between $l$ and $h$ must be equal to their price ratio (including the price paid for allowances).

Define the following: $d_{l} \equiv(1-\alpha)\left(P_{l}+\hat{\lambda} \mu_{l}\right)$ and $d_{h} \equiv \alpha\left(P_{h}+\hat{\lambda} \mu_{h}\right)$ and substitute into (A5)

$$
\frac{\widehat{h}}{\hat{l}}=\frac{(1-\alpha)\left(P_{l}+\hat{\lambda} \mu_{l}\right)}{\alpha\left(P_{h}+\hat{\lambda} \mu_{h}\right)}=\frac{d_{l}}{d_{h}}
$$

Solving (A6) and (A0), we obtain the conditional factor demand functions 


$$
l=\frac{d_{h}}{d_{h} \mu_{l}+d_{l} \mu_{h}} B, h=\frac{d_{l}}{d_{h} \mu_{l}+d_{l} \mu_{h}} B
$$

Substituting $l$ and $h$ from Eq.(A7) back into (A4) yields:

$$
P_{e}=\frac{1}{G \alpha(1-\alpha)} d_{h}^{1-\alpha} d_{l}^{\alpha}
$$

Differentiating (A8) with respect to $\lambda$

$$
\frac{\partial \lambda}{\partial P_{e}}=G \frac{d_{h}^{\alpha} d_{l}^{1-\alpha}}{\mu_{h} d_{l}+\mu_{l} d_{h}}>0
$$

The inequality (A9) clearly holds for all values of $P_{e}, d_{h}$ and $d_{l}$.

Differentiating (A9) with respect to $\lambda$ defines the key derivative of the theorem as

$$
\frac{\partial^{2} \lambda}{\partial P_{e}^{2}}=G\left(\frac{\partial \lambda}{\partial P_{e}}\right) \frac{d_{h}^{\alpha} d_{l}^{1-\alpha}}{\left(\mu_{h} d_{l}+\mu_{l} d_{h}\right)^{2}}\left(\alpha^{2} \mu_{h} \mu_{l}+(1-\alpha)^{2} \mu_{h} \mu_{l}+\alpha^{2} \mu_{h}^{2}\left(\frac{d_{l}}{d_{h}}\right)+(1-\alpha)^{2} \mu_{l}^{2}\left(\frac{d_{h}}{d_{l}}\right)-\mu_{h} \mu_{l}\right)
$$

Let $d=d_{l} / d_{h}$. Note that the minimum value of $\alpha^{2} \mu_{h}^{2} d+(1-\alpha)^{2} \mu_{l}^{2}\left(\frac{1}{d}\right)$ in the last bracketed term of (A10) equals $2 \alpha(1-\alpha) \mu_{h} \mu_{l}$ evaluated at $d=\frac{(1-\alpha) \mu_{l}}{\alpha \mu_{h}}$.

Since by construction, there is $d=\frac{(1-\alpha)\left(P_{l}+\lambda \mu_{l}\right)}{\alpha\left(P_{h}+\lambda \mu_{h}\right)}>\frac{(1-\alpha) \mu_{l}}{\alpha \mu_{h}}$, then $\alpha^{2} \mu_{h}^{2} x+(1-\alpha)^{2} \mu_{l}^{2}\left(\frac{1}{x}\right)>2 \alpha(1-\alpha) \mu_{h} \mu_{l}$. Thus $\frac{\partial^{2} \lambda}{\partial P_{e}^{2}}>0$, which proves the convexity of the marginal value of permits with respect to electricity price (recalling that $\lambda$ is the Lagrangian multiplier and represents the marginal valuation of a unit of permit).

\section{(B) CES Production Function}

Next consider a more general CES production function

$$
g=G\left(\alpha l^{\rho}+(1-\alpha) h^{\rho}\right)^{\frac{1}{\rho}}
$$

where $\rho<1, \eta=\frac{1}{1-\rho}$ is the elasticity of substitution. $\alpha$ still reflects distribution weight of low-carbon fuel.

The first order conditions are: 


$$
\begin{gathered}
P_{e} G\left(\alpha \widehat{l}^{\rho}+(1-\alpha) \widehat{h}^{\rho}\right)^{\frac{1}{\rho}-1} \alpha \hat{l}^{\rho-1}-P_{l}-\hat{\lambda} \mu_{l}=0 \\
P_{e} G\left(\alpha \hat{l}^{\rho}+(1-\alpha) \widehat{h}^{\rho}\right)^{\frac{1}{\rho}-1}(1-\alpha) \hat{h}^{\rho-1}-P_{h}-\hat{\lambda} \mu_{h}=0
\end{gathered}
$$

Cross-dividing (A13) and (A14), the factor proportion at the optimum is determined by

$$
\frac{l}{h}=\left(\frac{(1-\alpha)\left(P_{l}+\lambda \mu_{l}\right)}{\alpha\left(P_{h}+\lambda \mu_{h}\right)}\right)^{\frac{1}{\rho-1}} \equiv\left(\frac{d_{l}}{d_{h}}\right)^{\frac{1}{\rho-1}}
$$

As before, solve $l$ and $h$ from (A15) and (A0) and substitute them into (A13)

$$
P_{e}=\frac{1}{G \alpha(1-\alpha)}\left(\alpha d_{l}^{\frac{\rho}{\rho-1}}+(1-\alpha) d_{h}^{\frac{\rho}{\rho-1}}\right)^{\frac{\rho-1}{\rho}}
$$

Taking partial derivative of (A13) with respect to $\lambda$ gives

$$
\frac{\partial \lambda}{\partial P_{e}}=G \frac{\left(\alpha d_{l}^{\frac{\rho}{\rho-1}}+(1-\alpha) d_{h}^{\frac{\rho}{\rho-1}}\right)^{\frac{1}{\rho}}}{\left(\mu_{l} d_{l}^{\frac{1}{\rho-1}}+\mu_{h} d_{h}^{\frac{1}{\rho-1}}\right)}>0
$$

Apparently, (A17) holds for all values of $P_{e}, d_{h}$ and $d_{l}$.

Differentiate (A17) with respect to $\lambda$ gives:

$$
\frac{\partial^{2} \lambda}{\partial P_{e}^{2}}=G \frac{\left(\alpha d_{l}^{\frac{\rho}{\rho-1}}+(1-\alpha) d_{h}^{\frac{\rho}{\rho-1}}\right)^{\frac{1-\rho}{\rho}}}{(1-\rho)\left(\mu_{l} d_{l}^{\frac{1}{\rho-1}}+\mu_{h} d_{h}^{\frac{1}{\rho-1}}\right)^{2}}\left(\frac{\partial \lambda}{\partial P_{e}}\right) T_{1}
$$

where $T_{1} \equiv d_{l}^{\frac{1}{\rho-1}} d_{h}^{\frac{1}{\rho-1}}\left(\alpha^{2} \mu_{h}^{2}\left(\frac{d_{l}}{d_{h}}\right)+(1-\alpha)^{2} \mu_{l}^{2}\left(\frac{d_{h}}{d_{l}}\right)-2 \alpha(1-\alpha) \mu_{l} \mu_{h}\right)$

Note that (A19) has a similar structure to that of the last bracketed term of (A10). Following the same procedure, we see that because $\frac{P_{l}+\lambda \mu_{l}}{P_{h}+\lambda \mu_{h}}>\frac{\mu_{l}}{\mu_{h}}, T_{1}>0$. Then it is sufficient to show that $\frac{\partial^{2} \lambda}{\partial P_{e}^{2}}>0$. Therefore, given a more general form of production function, the marginal value of allowances is still convex in $P_{e}$. 


\section{Appendix B.}

PROOF. The Marginal Value of Allowances is Convex in InPut Costs $P_{l}$ and $P_{h}$.

Following previous discussion, substitute $d_{l} \equiv(1-\alpha)\left(P_{l}+\hat{\lambda} \mu_{l}\right)$ and $d_{h} \equiv \alpha\left(P_{h}+\hat{\lambda} \mu_{h}\right) \quad$ into Eq.(A7) to obtain $\lambda$ as an implicit function of $P_{e}$

$$
P_{l}+\lambda \mu_{l}=\frac{1}{1-\alpha}\left[G \alpha(1-\alpha) P_{e}\right]^{\frac{1}{\alpha}} \alpha^{\frac{\alpha-1}{\alpha}}\left(P_{h}+\lambda \mu_{h}\right)^{\frac{\alpha-1}{\alpha}}
$$

Taking partial derivative of (A13) with respect to $P_{l}$ and $\lambda$ gives

$$
\frac{\partial \lambda}{\partial P_{l}}=-\frac{1}{\left[G(1-\alpha) P_{e}\right]^{\frac{1}{\alpha}}\left(P_{h}+\lambda \mu_{h}\right)^{-\frac{1}{\alpha}} \mu_{h}+\mu_{l}}<0
$$

Differentiate Eq.(A14) with respect to $\lambda$

$$
\frac{\partial^{2} \lambda}{\partial P_{l}^{2}}=-\frac{\frac{1}{\alpha}\left[G(1-\alpha) P_{e}\right]^{\frac{1}{\alpha}}\left(P_{h}+\lambda \mu_{h}\right)^{-\frac{1}{\alpha}-1} \mu_{h}^{2}}{\left(\left[G(1-\alpha) P_{e}\right]^{\frac{1}{\alpha}}\left(P_{h}+\lambda \mu_{h}\right)^{-\frac{1}{\alpha}} \mu_{h}+\mu_{l}\right)^{2}} \frac{\partial \lambda}{\partial P_{l}}>0
$$

The inequality follows naturally. So $\lambda$ is also a convex function of $P_{l}$. Similarly, we can show that $\lambda$ is convex in $P_{h}$. Therefore, increases in the mean preserving spread of $P_{l}$ and $P_{h}$ increases the expected marginal value of permits. 


\section{Appendix C.}

PROOF: In an imperfect electricity market, the marginal value of allowances is also convex in electricity prices.

Consider the following optimization problem for a firm with market power in electricity market described presented in the paper (Eq.[20])

$$
V=\max \left[W G^{\varepsilon} l^{\varepsilon \alpha} h^{\varepsilon(1-\alpha)}-P_{l} l-P_{h} h\right]
$$

s.t. $\quad B=e(l, h)=\gamma\left(\delta_{l} l+\delta_{h} h\right)=\mu_{l} l+\mu_{h} h$

where $\varepsilon=\frac{1}{\varphi} \leq 1, W$ is the stochastic demand shifter and $G$ is the productivity parameter.

The necessary first-order conditions for a maximum at $(\hat{l}, \hat{h}, \hat{\lambda})$ are

$$
\begin{aligned}
& W G^{\varepsilon} \varepsilon \alpha l^{\varepsilon \alpha-1} h^{\varepsilon(1-\alpha)}-P_{l}-\lambda \mu_{l}=0 \\
& W G^{\varepsilon} \varepsilon(1-\alpha) l^{\varepsilon \alpha} h^{\varepsilon(1-\alpha)-1}-P_{h}-\lambda \mu_{h}=0
\end{aligned}
$$

The MRT is unaffected by returns to scale and is again described by Eq.(A5). A similar exercise as in Appendix A provides the following condition where $d_{h}$ and $d_{l}$ are functions of $\lambda$.

$$
W=\frac{B^{1-\varepsilon}}{G^{\varepsilon} \varepsilon \alpha(1-\alpha)} d_{h}^{1-\varepsilon \alpha} d_{l}^{1-\varepsilon(1-\alpha)}\left(\mu_{h} d_{l}+\mu_{l} d_{h}\right)^{\varepsilon-1}
$$

Taking partial derivative of (A19) with respect to $\lambda$

$$
\frac{\partial \lambda}{\partial W}=G^{\varepsilon} \varepsilon \alpha(1-\alpha) B^{\varepsilon-1} d_{h}^{\varepsilon \alpha} d_{l}^{\varepsilon(1-\alpha)}\left(\mu_{h} d_{l}+\mu_{l} d_{h}\right)^{2-\varepsilon} T_{3}^{-1}
$$

Where

$$
T_{3}=\alpha(1-\alpha)\left(\mu_{h} d_{l}+\mu_{l} d_{h}\right)^{2}+(1-\varepsilon)\left(\alpha \mu_{h} P_{l}-(1-\alpha) \mu_{l} P_{h}\right)^{2}
$$

When $\varepsilon \leq 1$, there is still $\frac{\partial \lambda}{\partial W}>0$

The second order derivative of $\lambda$ with respect to $W$ is

where

$$
\frac{\partial^{2} \lambda}{\partial W^{2}}=G^{\varepsilon} \varepsilon \alpha(1-\alpha) B^{\varepsilon-1} d_{h}^{\varepsilon \alpha-1} d_{l}^{\varepsilon(1-\alpha)-1}\left(\mu_{h} d_{l}+\mu_{l} d_{h}\right)^{1-\varepsilon} T_{3}^{-2} T_{4} \frac{\partial \lambda}{\partial W}
$$




$$
\begin{gathered}
T_{4}=\varepsilon T_{3} d_{l} d_{h}\left[\alpha^{2} \mu_{h} \mu_{l}+(1-\alpha)^{2} \mu_{h} \mu_{l}+\alpha^{2} \mu_{h}^{2}\left(\frac{d_{l}}{d_{h}}\right)+(1-\alpha)^{2} \mu_{l}^{2}\left(\frac{d_{h}}{d_{l}}\right)-\mu_{h} \mu_{l}\right]+ \\
2(1-\varepsilon) \mu_{h} \mu_{l} d_{h} d_{l}\left(\alpha \mu_{h} P_{l}-(1-\alpha) \mu_{l} P_{h}\right)^{2}
\end{gathered}
$$

Consultation with Appendix A ought to reveal that $T_{4}>0$ because $\frac{P_{l}+\lambda \mu_{l}}{P_{h}+\lambda \mu_{h}}>\frac{\mu_{l}}{\mu_{h}}$, and $\alpha^{2} \mu_{h}^{2} x+(1-\alpha)^{2} \mu_{l}^{2}\left(\frac{1}{x}\right)>2 \alpha(1-\alpha) \mu_{h} \mu_{l}$. Therefore, $\frac{\partial^{2} \lambda}{\partial W} \geq 0$. Hence when electricity market is imperfect, the marginal value of permits is still convex in the underlying stochastic variable. 


\section{Appendix D Data Sources}

I obtained annual data on allowances initial allocations, holdings, transactions, and deductions (for emissions compliance purposes) from the EPA's allowance tracking system spanning from 1995 to 2004 for all 263 Phase I affected coal-fired generating units. I merged this dataset with information collected from FERC Form 767. FERC Form 767 is an annual survey on steam-electric plant unit operating and design covering the period 1996-2004, from which I took annual observations at the generating unit level on unit nameplate capacity, the status of scrubber installation, electricity generations, load hours, fuel consumption and monthly fuel sulfur content and heat content, Using information about fuel consumption, fuel heat content, total generation, along with the emission data derived from the EPA's allowance tracking system, I computed heat rate, heat input, and emission rate for each unit-year observation. Because data are missing for certain years, and because some units were not operating for an entire year, the number of observations varies from unit to unit.

The price information on fuel, electricity, natural gas, and allowances are obtained from different sources. To construct data on prices and input shares for low- and high-sulfur coal, the above merged data set was then merged with the Form FERC-423 on monthly cost and quality of coals for electric plants from 1995 to 2004. Form FERC-423 records the physical quantity, Btu content, delivered cost, and carbon content of each fuel transaction at each electric plant. $\mathrm{A} \mathrm{SO}_{2}$ emission boundary of 2.5 pounds per million Btu was used to distinguish low- and high-sulfur coal. This value was chosen so that the burning of low-carbon coal meets Phase I standards on average. Fuel prices are calculated by dividing the delivered cost by the heat content of the fuel. Fuel prices are missing for some plants when only one type of fuel is purchased (the price of the other fuel is unobservable). To obtain the cost of fuel that is not purchased by the plant, I use its price in the previous year as an approximation.

The electricity price data are drawn from the responses from electric utilities survey Form EIA-861 "Annual Electric Power Industry Report." From this data set, I obtained the annual average industrial price for all years from 1995 to 2004 at the state level. Industrial prices are the most volatile and least protected by PUC regulation. The volatility of industrial prices is mainly driven by changes in fuel costs. However, because of the existence of long-term contacts, to use industrial prices may underestimate the actual price volatility in the spot market. Natural gas wellhead prices were collected from EIA historical databases. $\mathrm{SO}_{2}$ regulation costs are calculated as the mean of two monthly price indices of $\mathrm{SO}_{2}$ allowances prices that brokerage firms Cantor Fitzgerald and Fieldston report to the EPA.

Distance to fuel mines was provided by the EPA's Acid Rain Division. Data on regulatory status were collected from the Retail Wheeling \& Restructuring Report, a state-by-state reporting of regulatory commissions, state legislation, and utilities activities related to retail competition published quarterly by the Edison Electric Institute. These data are crosschecked with the LEAP Letter published bimonthly by William A. Spratley \& Associates, National Regulatory Research Institute Web site and EIA's publication on Status of State Electric Industry Restructuring Activity. 


\section{Appendix E Stochastic Dynamic Simulation Model Description}

Here I present the computational details of the numerical simulation, programming language, hardware and software used. Consider the following optimization problem

$$
\begin{array}{ll}
V_{t}\left(P_{e t}, B_{t}\right) \equiv \max _{l_{t}, h_{t}, B_{t+1}}\left\{P_{e t} g_{t}\left(l_{t}, h_{t}\right)-c_{t}\left(l_{t}, h_{t}\right)+\beta E_{t}\left[V_{(t+1)}\left(P_{e(t+1)}, B_{t+1}\right)\right]\right. \\
\text { s.t. } \quad \mu_{l} l_{t}+\mu_{h} h_{t}=A_{t}+B_{t}-B_{t+1} \\
& 0 \leq B_{t+1} \leq A_{t}+B_{t}
\end{array}
$$

where $g_{t}=G\left(l_{t}^{\alpha} h_{t}^{(1-\alpha)}\right)^{\varepsilon}$.

This is a multivariate optimization problem with three control variables $(l, h$, and $B)$. To simplify the problem, I derive the structural relationship between $l, h$ and $B$ based on first-order conditions. This derivation, which involves some tedious calculation, ${ }^{32}$ leads to the following specifications:

(1) $\lambda_{t}$ is fully characterized by

$$
P_{e t}=\frac{\left(A_{t}+B_{t}-B_{t+1}\right)^{1-\varepsilon}}{G s \alpha(1-\alpha)} d_{h t}^{1-\varepsilon \alpha} d_{l t}^{1-\varepsilon(1-\alpha)}\left(\mu_{h} d_{l t}+\mu_{l} d_{h t}\right)^{\varepsilon-1}
$$

(2) $l_{t}$ and $h_{t}$ are determined by the following two static optimality equations

$$
l_{t}=\frac{d_{h t}}{d_{h t} \mu_{l}+d_{l t} \mu_{h}}\left(A_{t}+B_{t}-B_{t+1}\right), h_{t}=\frac{d_{l t}}{d_{h t} \mu_{l}+d_{l t} \mu_{h}}\left(A_{t}+B_{t}-B_{t+1}\right)
$$

Noting that now the problem is simplified as we only need to search for the solution for $B$, and find optimal choices for $l$ and $h$ using Eqs. (A25) and (A26). Applying a grid search to obtain the initial guess for $B\left(B^{*}<20\right)$ I then specify a grid of 2001 points between 1 and 20 (million tons) to compute the value function (A24) at each time $t$ and each state of $P_{\text {et }}$, beginning with the terminal value function and working back to period 1 to compute the equilibrium time path for $B$ and $\lambda$, which jointly determine the optimal choices for $l_{t}$ and $h_{t}$.

The program needed for the computation of the model was coded in $\mathrm{C}++$ and complied to run on Windows- based machines. The whole simulation runs in one minute. All the code is available upon request from the author.

\footnotetext{
${ }^{32}$ Available from the author, upon request.
} 
Figure I

AnNual Emission Cap, AgGRegated Emissions and BanKed Allowances

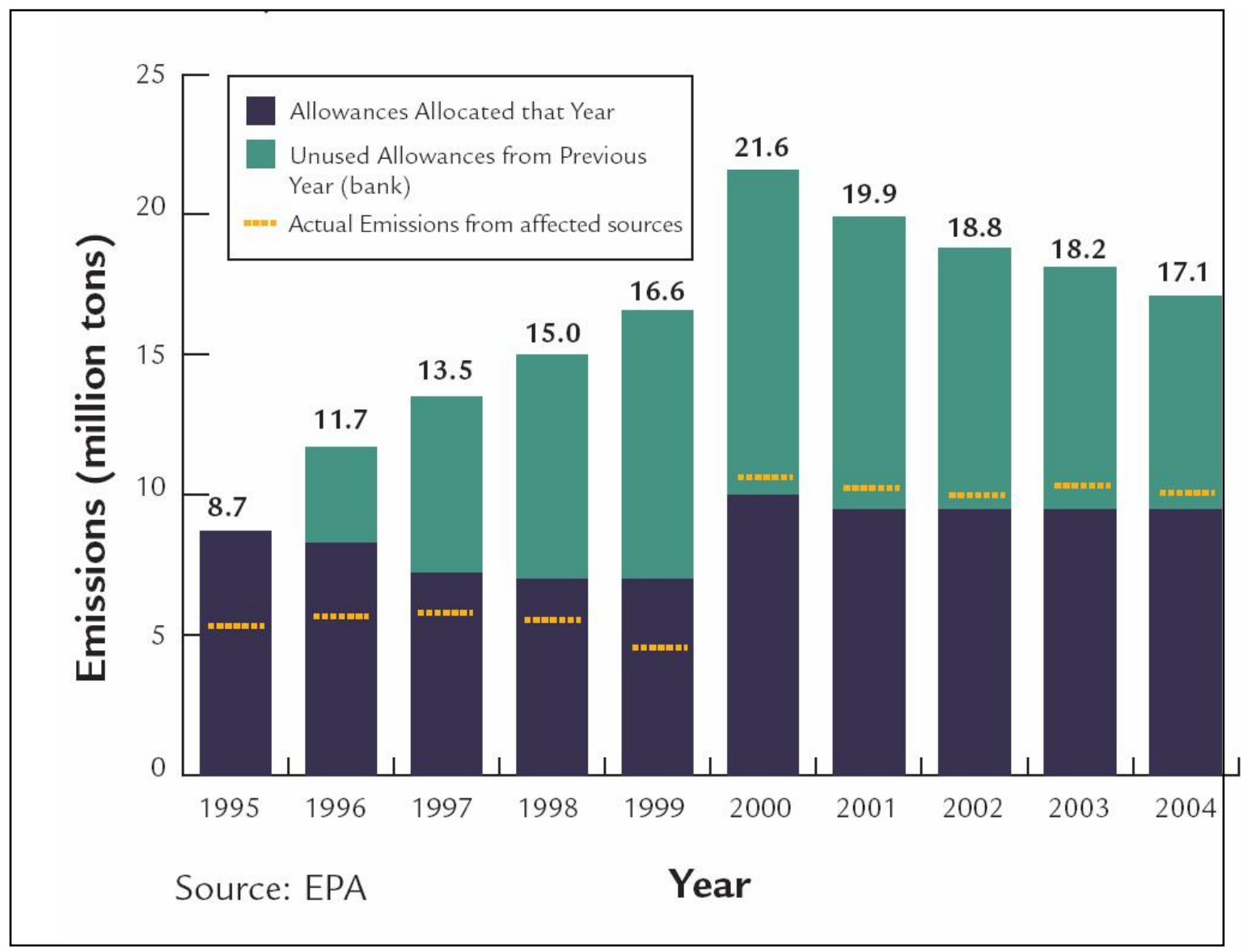


FIGURE II

Aggregate Banked Allowances under Different Price Volatilities

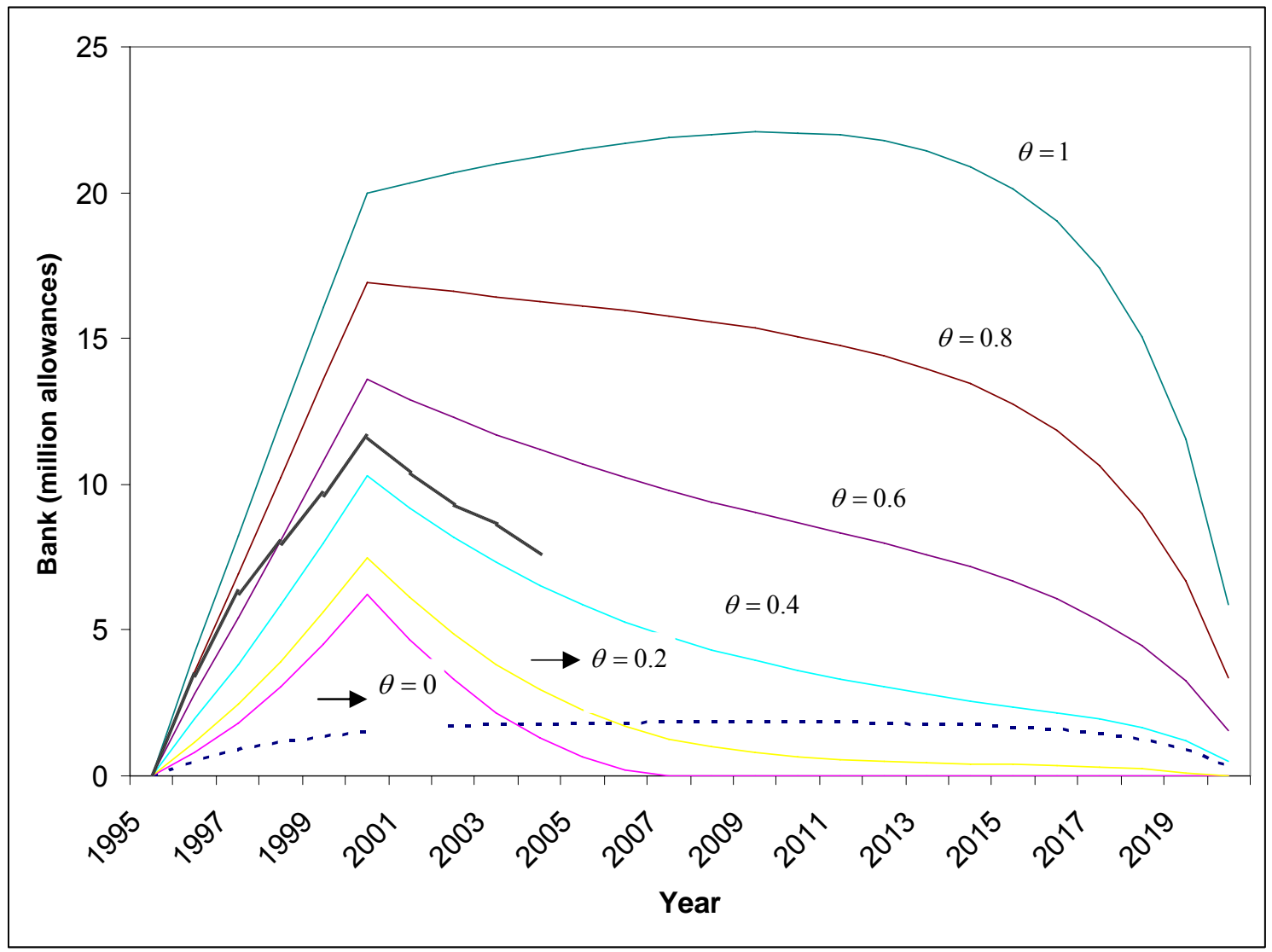

NoTE: The vertical axis describes the total amount of banked permits of the polluting industry in each year (million tons). $\theta$ is the mean-preserving spread of the stochastic electricity price. The dashed line corresponds to a scenario that $\theta=0.2$ and the emission cap remains constant at 7 million tons across all years. The shaded, fuzzy line tracks actual allowance stock in the SO2 allowance market. All the other lines correspond to a two-stage schedule of declining emission standards with total emissions capped at 7 million tons from 1995 to 1997 and at 3.5 million tons after year 2000 . 
FIGURE III

EMISSION STREAm UNDER DifFERENT PRICE Volatilities

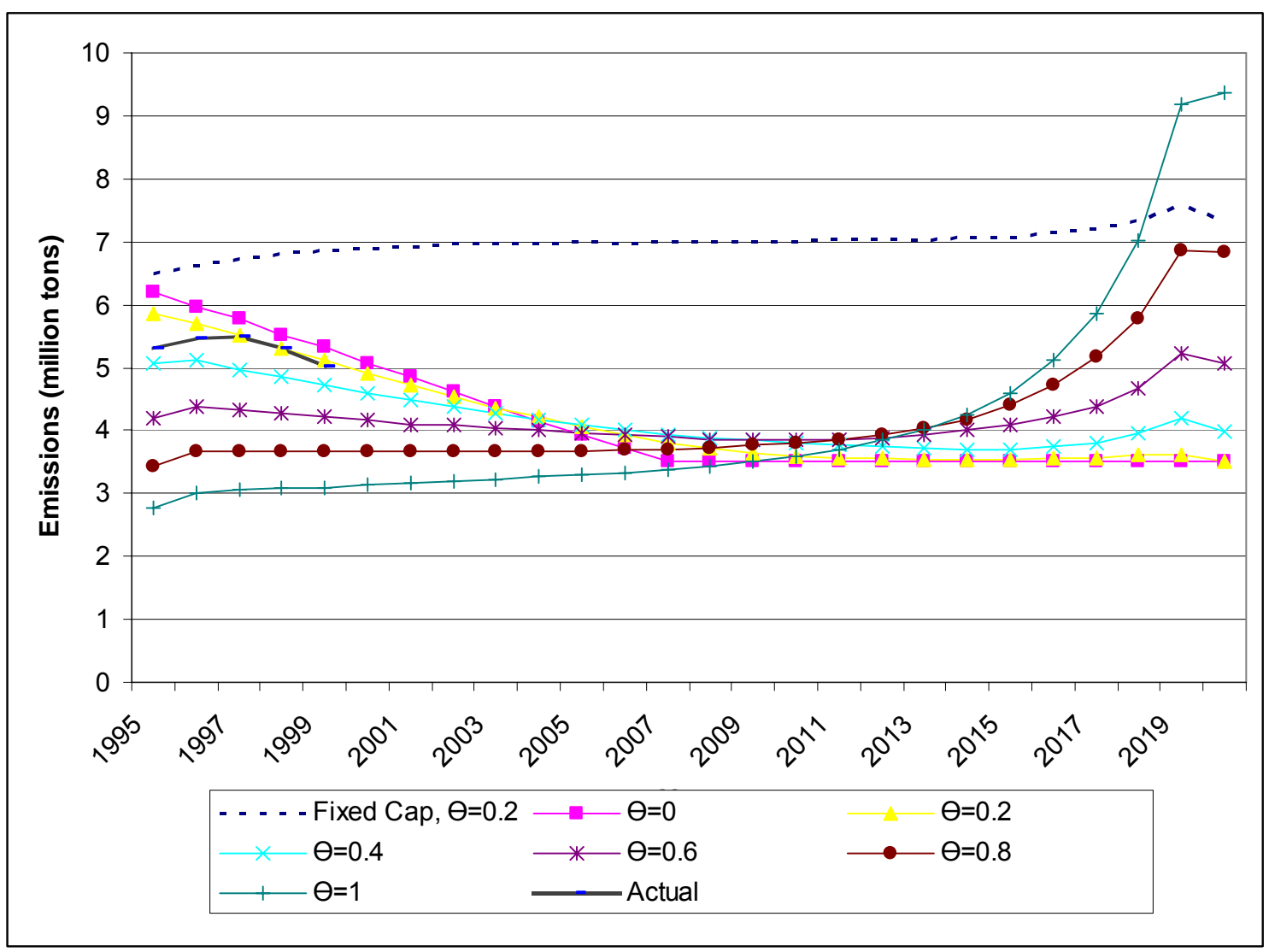

NOTE: The vertical axis describes the aggregate annual emissions of the industry (million tons). $\theta$ is the mean-preserving spread of the stochastic electricity price. The dashed line corresponds to a scenario in which $\theta=0.2$ and the emission cap remains constant at 7 million tons across all years. All the other lines correspond to a two-stage schedule of declining emission standards with total emissions capped at 7 million tons from 1995 to 1997 and at 3.5 million tons after year 2000 . 
FIGURE IV

Cumulative EMissions Under DifFERENT PRice VolatiLities

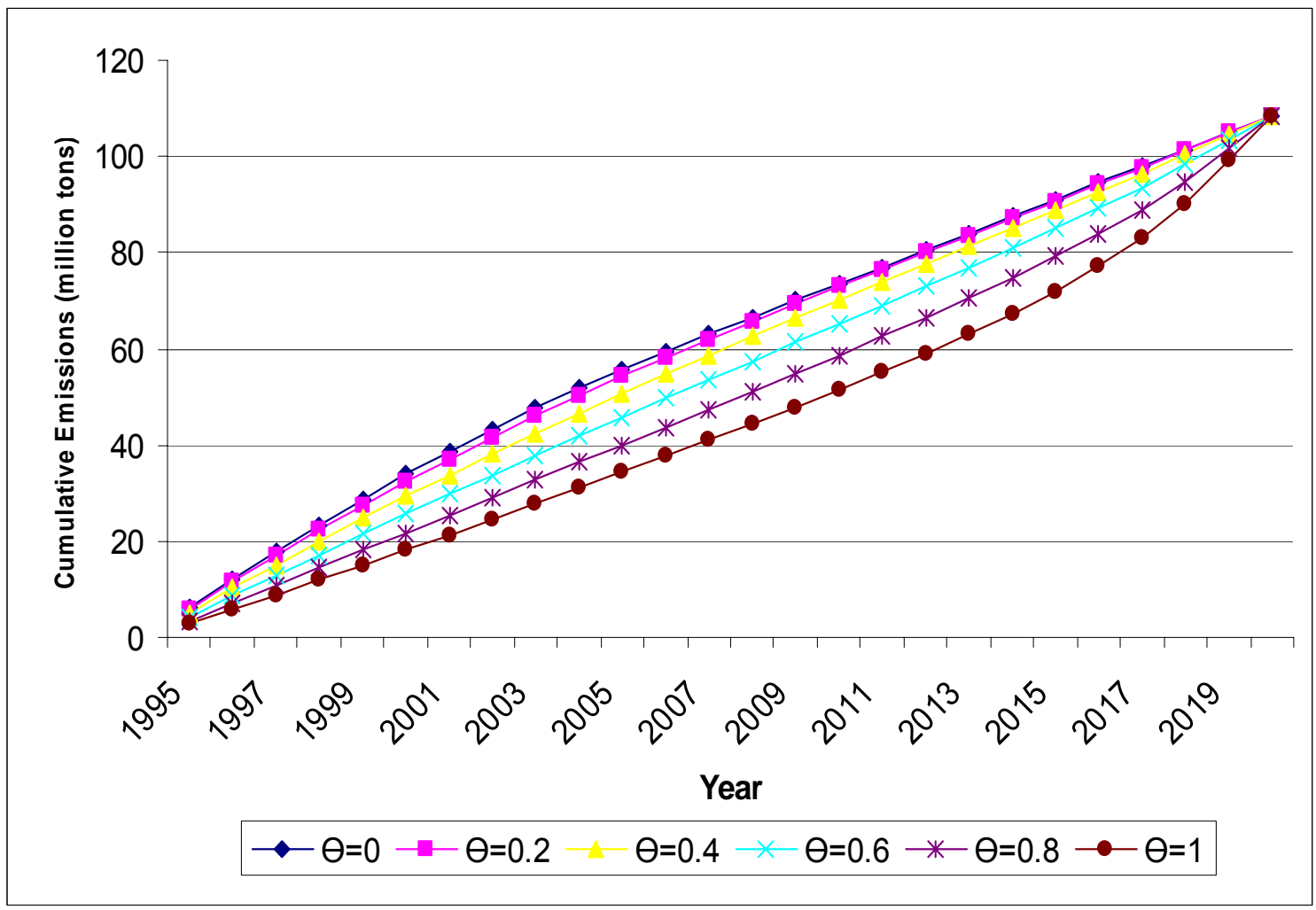

NotE: The vertical axis describes the cumulative emissions in each year (million tons). $\theta$ is the mean-preserving spread of stochastic electricity price. The dashed line corresponds to a scenario in which $\theta=0.2$ and the emission cap remains constant at 7 million tons across all years. All the other lines correspond to a two-stage schedule of declining emission standards with total emissions capped at 7 million tons from 1995 to 1997 and at 3.5 million tons after year 2000 . 
FIGURE V

Permit Price Path under Different Price Volatilities

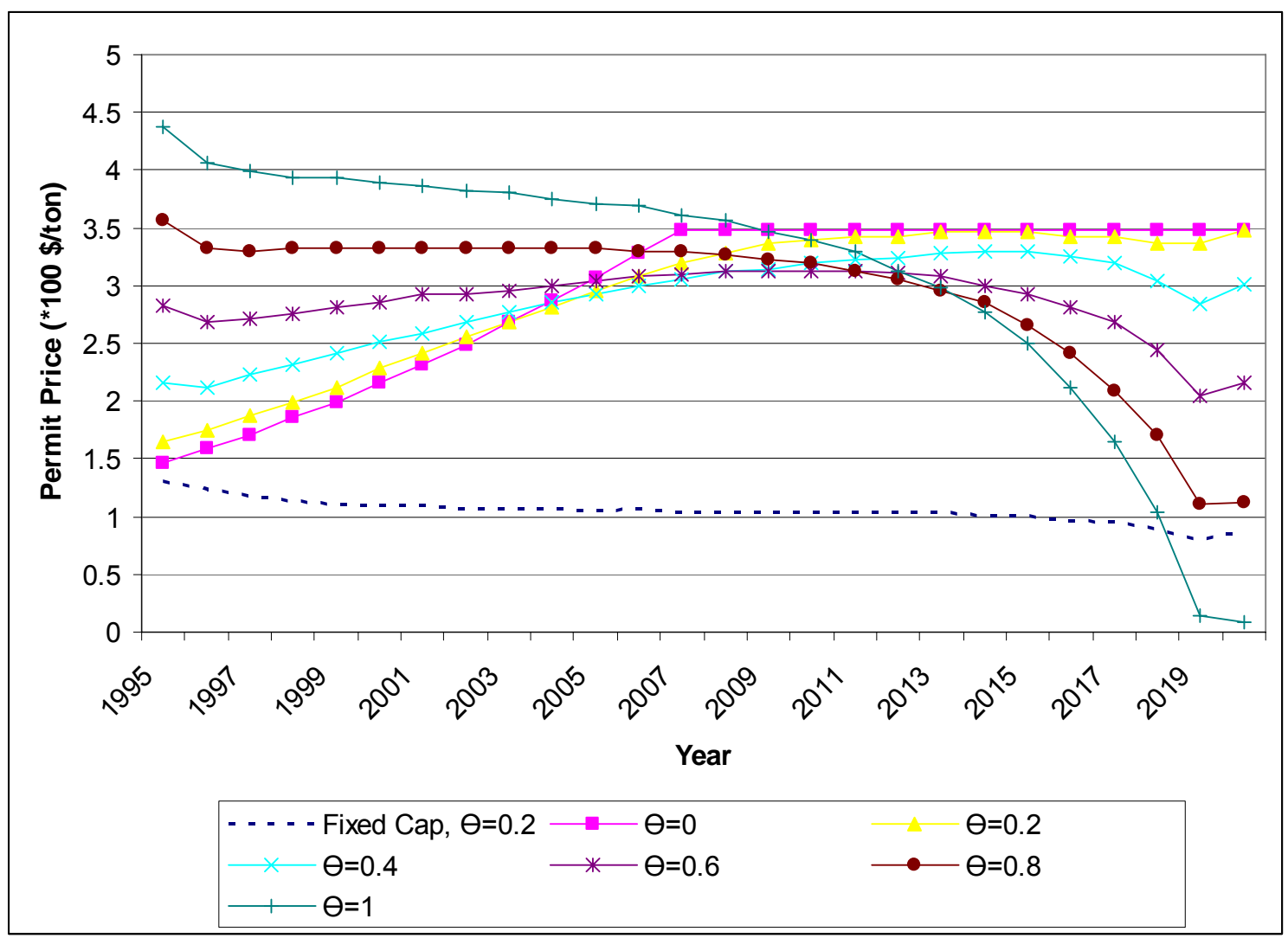

NoTE: The vertical axis describes the real term emission price (x100 \$/ton). $\theta$ is the meanpreserving spread of stochastic electricity price. The dashed line corresponds to a scenario in which $\theta=0.2$ and the emission cap remains constant at 7 million tons across all years. The shaded, fuzzy line tracks actual allowance stock in the SO2 allowance market. All the other lines correspond to a two-stage schedule of declining emission standards with total emissions capped at 7 million tons from 1995 to 1997 and at 3.5 million tons after year 2000 . 
FIGURE VI

EMISSIONS PATH UNDER CHANGING PRICE VOLATILITY

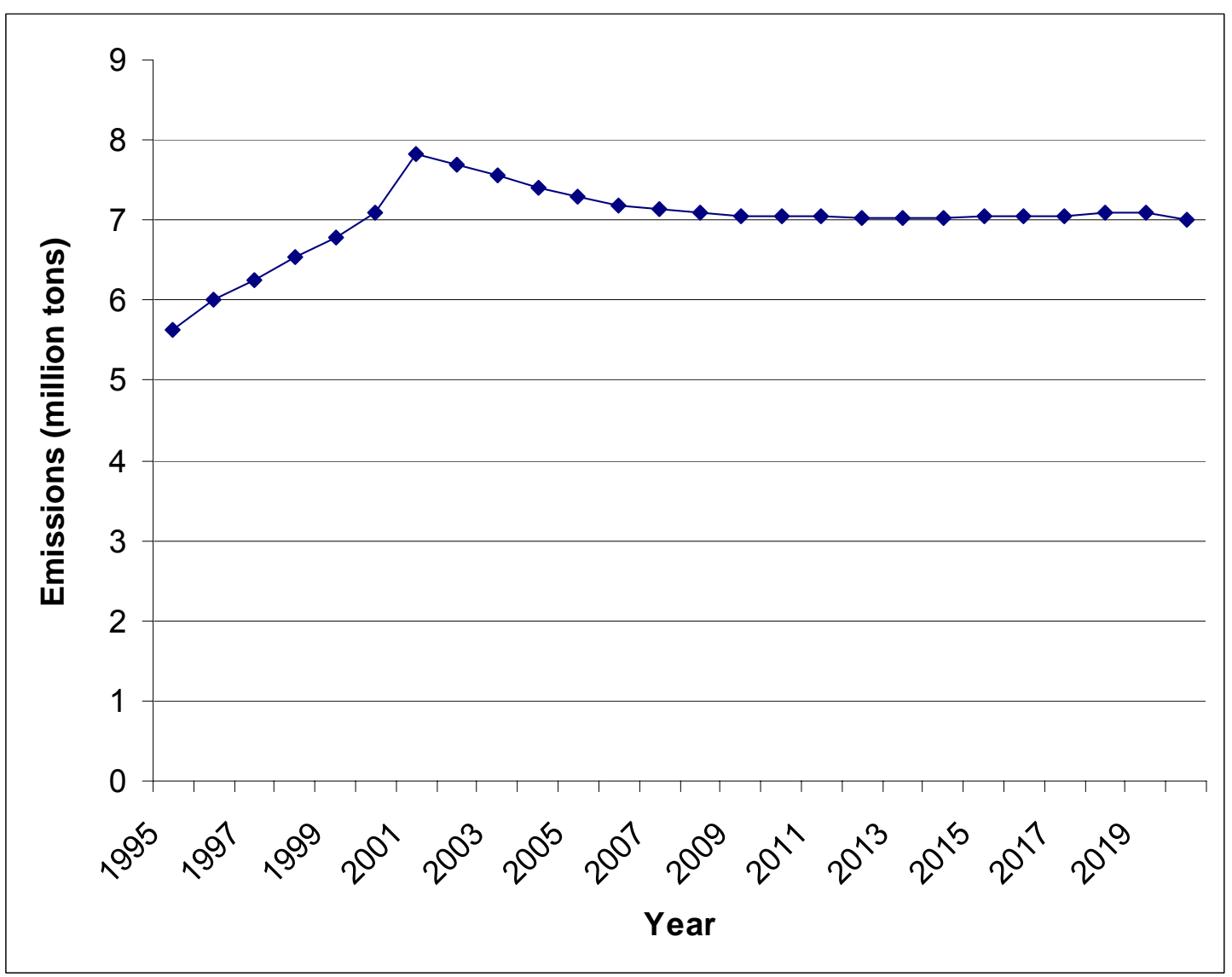

NotE: The graphs describes emission path under a scenario in which the price spread $\theta=0.2$ from 1995 to 2002 and drops to $\theta=0.4$ through 2020 . 


\section{Table I. DEFINITION OF THE SYMBOLS}

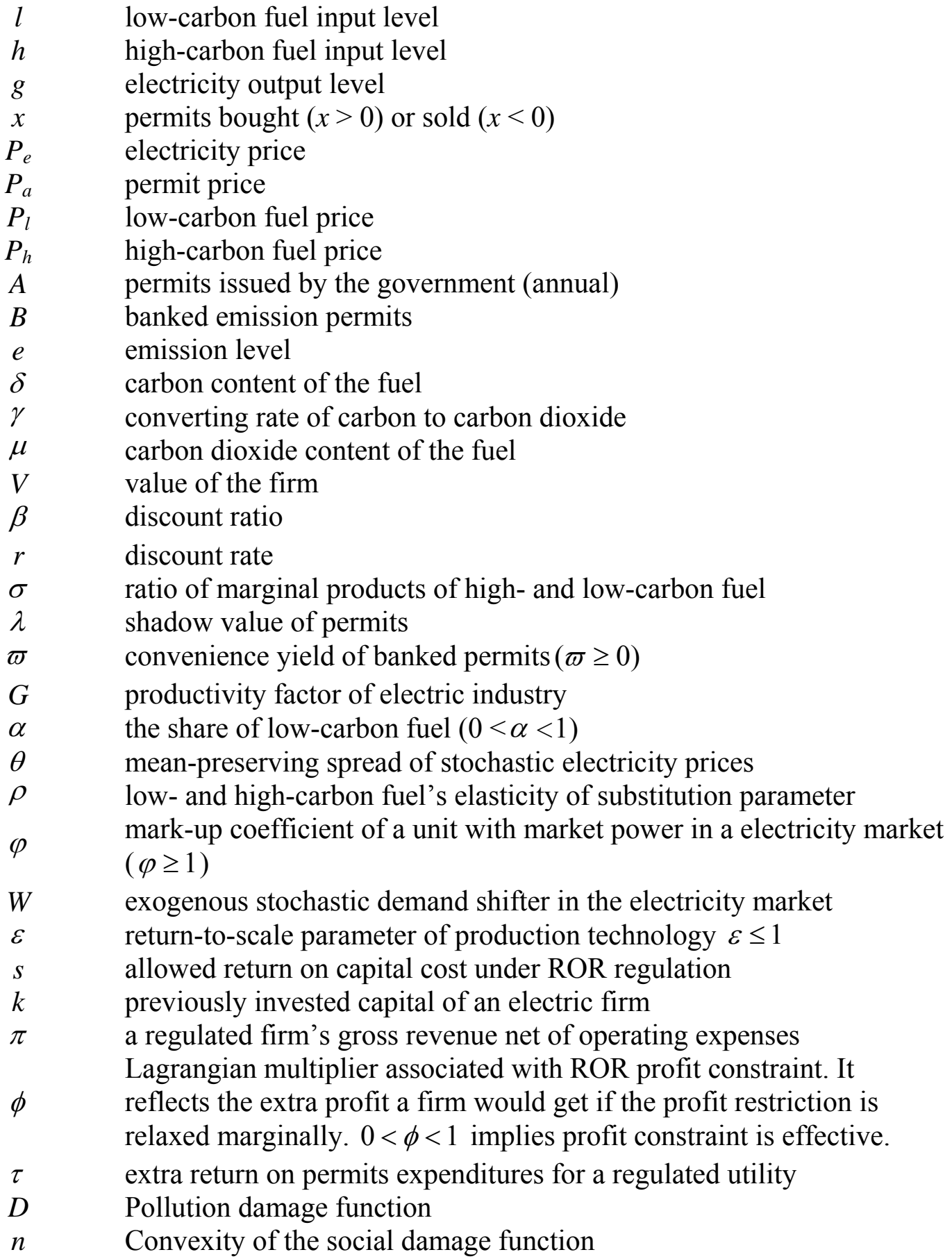


Table II

SUMMARY STATISTICS

\begin{tabular}{|c|c|c|c|c|c|}
\hline Variables & Obs. & Mean & Std. Dev. & Min & Max \\
\hline Emissionrate(tons/MWh) & 1595 & .011 & .007 & .00008 & .041 \\
\hline$\Delta P_{e}(\%)$ & 1595 & .050 & .037 & .014 & .170 \\
\hline $\mathrm{P}_{\mathrm{a}}($ dollars/ton $)$ & 1595 & 133 & 55 & 80 & 285 \\
\hline $\mathrm{P}_{\mathrm{e}}($ cents/KWh $)$ & 1595 & 4.21 & .95 & 2.68 & 9.54 \\
\hline $\mathrm{P}_{1}($ cents $/ \mathrm{mmBTU})$ & 1595 & 127.8 & 28.0 & 71.3 & 279 \\
\hline $\mathrm{P}_{\mathrm{h}}($ cents $/ \mathrm{mmBTU})$ & 1595 & 126.7 & 43.2 & 76.7 & 418.6 \\
\hline $\mathrm{P}_{\mathrm{ng}}($ dollars/thousand cubic feet $)$ & 1595 & 2.97 & 1.34 & 1.77 & 5.45 \\
\hline Vintage & 1595 & 1964 & 7.8 & 1949 & 1978 \\
\hline AGE (years) & 1595 & 36 & 8.1 & 18 & 55 \\
\hline HEATERATE(mmBTU/MWh) & 1595 & 10.23 & 1.05 & 2.50 & 17.90 \\
\hline WORKLOAD (hours) & 1595 & 7253.5 & 1077.8 & 792 & 8760 \\
\hline Initial (tons) & 1595 & 17467 & 17877 & 144 & 192637 \\
\hline Carry (tons) & 1595 & 11187 & 18472 & 0 & 155236 \\
\hline Stock (tons) & 1595 & 29653 & 27153 & 343 & 277612 \\
\hline MUNI & 1595 & .021 & .144 & 0 & 1 \\
\hline CAP (MW) & 1595 & 356 & 254 & 75 & 1300 \\
\hline$\left.\delta_{l}(\mathrm{lbs} / \mathrm{mmBTU})\right)$ & 1452 & 1.64 & .68 & 0.41 & 2.98 \\
\hline$\left.\delta_{h}(\mathrm{lbs} / \mathrm{mmBTU})\right)$ & 1452 & 4.41 & 1.28 & 3.00 & 8.95 \\
\hline DPRB (miles) & 1461 & 1063 & 327 & 87 & 1773 \\
\hline RTE93(lbs/mmBTU) & 864 & 2.32 & 1.79 & .01 & 8.06 \\
\hline
\end{tabular}


TABLE III

YEARLy OBSERVATIONS ON REgULATORY STATUSES, SCRUBBER INSTALLATION AND FUEL SWITCHING/BLENDING

\begin{tabular}{cccccc}
\hline \hline Year & Retail Access & Transit & Scrubber & Switch & No-blend \\
\hline 1996 & 28 & 165 & 23 & 34 & 21 \\
1997 & 44 & 141 & 23 & 38 & 15 \\
1998 & 58 & 127 & 23 & 35 & 23 \\
1999 & 105 & 83 & 21 & 54 & 8 \\
2000 & 87 & 85 & 21 & 56 & 15 \\
2001 & 55 & 85 & 17 & 40 & 3 \\
2002 & 55 & 84 & 19 & 65 & 11 \\
2003 & 49 & 85 & 16 & 50 & 13 \\
2004 & 49 & 86 & 17 & 36 & 7 \\
\hline \hline
\end{tabular}

Note: This table shows annual observations on the number of units affected by retail restructuring, installed scrubbers, switch to low-sulfur coal, or with no fuel blending. After 1998, because many generating units were divestitured to non-utilities and are no longer reporting fuel purchasing costs to the public, the sample size shrinks, which is reflected by the decreasing observation numbers of all variables. 
TABLE IV

DETERMINANTS OF EMISSION RATE (IN LOG FORM)

\begin{tabular}{|c|c|c|c|c|c|c|}
\hline Variables & (1) & (2) & (3) & (4) & (5) & (6) \\
\hline \multirow{2}{*}{$\Delta P_{e}$} & $-.878 * *$ & $-.858 * *$ & $-.865^{* *}$ & $-.937 * *$ & $-.896^{* *}$ & $-.901 * *$ \\
\hline & $(.401)$ & $(.335)$ & $(.307)$ & $(.365)$ & (.409) & $(.407)$ \\
\hline \multirow[t]{2}{*}{$\ln \mathrm{P}_{\mathrm{a}}$} & -.031 & -.051 & $-1.807 * * *$ & -.024 & $-.196^{* *}$ & - \\
\hline & $(.065)$ & $(.060)$ & $(.478)$ & $(.038)$ & $(.079)$ & \\
\hline \multirow[t]{2}{*}{$\ln \mathrm{P}_{\mathrm{e}}$} & -.269 & -.249 & -.221 & $-.234 * *$ & -153 & -.305 \\
\hline & $(.224)$ & $(.177)$ & $(.163)$ & $(.118)$ & $(.252)$ & $(.222)$ \\
\hline \multirow{2}{*}{$\ln \mathrm{P}_{1}$} & .047 & $.139 *$ & .008 & .046 & .016 & -.003 \\
\hline & $(.086)$ & $(.076)$ & $(.075)$ & $(.100)$ & $(.094)$ & $(.106)$ \\
\hline \multirow{2}{*}{$\ln \mathrm{P}_{\mathrm{h}}$} & .103 & .041 & $.118 * *$ & $.103 *$ & .133 & .037 \\
\hline & $(.089)$ & $(.058)$ & $(.056)$ & $(.051)$ & $(.091)$ & $(.085)$ \\
\hline \multirow[t]{2}{*}{ RetailAccess } & -.047 & -.059 & -.048 & .092 & .009 & -.030 \\
\hline & $(.051)$ & $(.039)$ & $(.035)$ & $(.046)$ & $(.064)$ & $(.050)$ \\
\hline \multirow[t]{2}{*}{ Transit } & .069 & .073 & .073 & -.054 & .083 & -.005 \\
\hline & $(.042)$ & $(.085)$ & $(.079)$ & $(.050)$ & $(.096)$ & $(.061)$ \\
\hline \multirow[t]{2}{*}{ SCRUBBER } & $-2.447 * * *$ & $-2.158 * * *$ & $-2.313 * * *$ & $-.396^{* *}$ & $-2.442 * * *$ & $-2.138 * * *$ \\
\hline & $(.036)$ & $(.081)$ & $(.138)$ & $(.068)$ & $(.038)$ & $(.031)$ \\
\hline \multirow[t]{2}{*}{ AGE } & -.023 & -.006 & -.023 & .008 & -.003 & .012 \\
\hline & $(.026)$ & $(.017)$ & $(.019)$ & $(.019)$ & $(.026)$ & $(.035)$ \\
\hline \multirow[t]{2}{*}{ AGE2 } & -.00009 & -.0002 & -.0001 & -.0003 & -.00009 & -.0004 \\
\hline & $(.0003)$ & $(.0002)$ & $(.0002)$ & $(.0002)$ & $(.0003)$ & $(.0005)$ \\
\hline \multirow{2}{*}{ InHEATRATE } & $.163^{*}$ & $.271 * *$ & .133 & -.247 & $.234 * *$ & $.231 * *$ \\
\hline & $(.098)$ & $(.114)$ & $(.110)$ & $(.205)$ & $(.094)$ & $(.089)$ \\
\hline \multirow[t]{2}{*}{ WORKLOAD } & -.053 & -.085 & -.059 & -.092 & -.013 & -.139 \\
\hline & $(.088)$ & $(.075)$ & $(.070)$ & $(.068)$ & $(.092)$ & $(.095)$ \\
\hline \multirow[t]{2}{*}{ INITIAL } & $1.20 \mathrm{e}-06$ & $1.31 \mathrm{e}-06$ & $1.18 \mathrm{e}-06$ & $-3.62 e-07$ & $8.85 e-07$ & $1.20 \mathrm{e}-06$ \\
\hline & $(9.33 e-07)$ & $(9.55 \mathrm{e}-07)$ & $(8.83 e-07)$ & $(4.04 \mathrm{e}-07)$ & $(9.74 \mathrm{e}-07)$ & $(1.90 \mathrm{e}-06)$ \\
\hline \multirow[t]{2}{*}{ MUNI $\Delta P_{e}$} & $.245^{* *}$ & .113 & $.245^{* *}$ & $.135^{* *}$ & $.236^{* *}$ & .104 \\
\hline & $(.095)$ & $(.107)$ & $(.112)$ & $(.042)$ & $(.099)$ & $(.077)$ \\
\hline CAP & - & $\begin{array}{r}-1.691 \\
(1.846)\end{array}$ & - & - & - & - \\
\hline CAP2 & - & $\begin{array}{r}.061 \\
(.173)\end{array}$ & - & - & - & - \\
\hline Constant & $\begin{array}{r}-7.258 * * * \\
(.660)\end{array}$ & $\begin{array}{r}264.390 * * * \\
(97.189)\end{array}$ & - & $\begin{array}{r}-17.074 \\
(4.224)\end{array}$ & $\begin{array}{r}-11.209 * * * \\
(.858)\end{array}$ & $\begin{array}{r}-4.959 * * * \\
(1.013)\end{array}$ \\
\hline $\mathrm{R}^{2}$ & .930 & .717 & .929 & .961 & .859 & .944 \\
\hline Observations & 1586 & 1586 & 1552 & 1032 & 1291 & 871 \\
\hline
\end{tabular}

NotE: Dependent Variable is Ln(emissionrate). Columns (1) and (2) report results from estimating Eq.(31) via the fixed effects and random effects models. A Hausman test rejects the null hypothesis that there is no systematic difference between fixed and random effects estimations. The test statistics are $\chi^{2}(19)=61.84, P$-value $=.0000$. Column (3) reports IV/2SLS estimation using natural gas wellhead price as an instrument for $\mathrm{SO}_{2}$ allowance price. $F$ statistic for the first stage regression is 22.08. Column (4) reports fixed effects estimation for Eq.(33). The sample is composed of 118 units that were operating in 1993. Column (5) reports estimation results based on a balanced panel dataset, which restricts the sample to 145 units that were active from 1996 to 2004. Column (6) reports estimation based on sample data from 1998 to 2003. Standard errors clustered by unit are reported in parentheses. $* * *$ indicates significant at the $1 \%$ level; ** indicates significant at the 5\% level; * indicates significant at the $10 \%$ level. Reported $R^{2}$ is the adjusted $R^{2}$ for fixed effects and random effects models and the centered $R^{2}$ for the IV/2SLS model. 
TABLE V

Determinants of Annual Percentage Change in Allowance Stock

\begin{tabular}{|c|c|c|c|c|c|}
\hline Variables & $(1)$ & (2) & (3) & (4) & (5) \\
\hline \multirow{2}{*}{$\Delta P_{e}$} & $2.410^{* *}$ & $2.457^{* *}$ & $2.358^{* *}$ & $2.759^{* *}$ & $1.615 * *$ \\
\hline & $(1.059)$ & (1.108) & (1.088) & (1.408) & $(.509)$ \\
\hline \multirow{2}{*}{$\ln \mathrm{P}_{\mathrm{a}}$} & -.171 & $-.216^{*}$ & $-.294 * *$ & - & $-.327 * * *$ \\
\hline & $(.113)$ & $(.118)$ & $(.133)$ & & $(.093)$ \\
\hline \multirow[t]{2}{*}{$\ln \mathrm{P}_{\mathrm{e}}$} & .135 & .369 & .249 & .389 & -.169 \\
\hline & $(.416)$ & $(.586)$ & $(.385)$ & $(.671)$ & (.287) \\
\hline \multirow[t]{2}{*}{$\ln \mathrm{P}_{1}$} & -.235 & -.110 & -.327 & -.073 & -..013 \\
\hline & $(.361)$ & $(.206)$ & $(.343)$ & $(.279)$ & (.093) \\
\hline \multirow[t]{2}{*}{$\ln P_{h}$} & -.021 & -.021 & -.020 & .007 & -.117 \\
\hline & $(.114)$ & $(.151)$ & (.109) & (.199) & (.097) \\
\hline \multirow[t]{2}{*}{ RetailAccess } & .085 & .101 & .140 & .119 & -.012 \\
\hline & $(.120)$ & $(.126)$ & $(.122)$ & $(.358)$ & $(.229)$ \\
\hline \multirow[t]{2}{*}{ Transit } & -.078 & -.077 & -.143 &.- .051 & -.117 \\
\hline & $(.108)$ & $(.286)$ & $(.154)$ & $(.104)$ & $(.231)$ \\
\hline \multirow[t]{2}{*}{ SCRUBBER } & $-.520 * * *$ & .043 & $-.338^{* *}$ & $-.666 * * *$ & $-.491 * *$ \\
\hline & $(.052)$ & $(.126)$ & $(.126)$ & $(.045)$ & $(.050)$ \\
\hline \multirow{2}{*}{ AGE } & .028 & .035 & .041 & $.111^{*}$ & .023 \\
\hline & $(.035)$ & $(.041)$ & $(.034)$ & $(.051)$ & $(.033)$ \\
\hline \multirow[t]{2}{*}{ AGE2 } & -.0006 & -.0006 & -.0005 & $-.002 * *$ & .00002 \\
\hline & $(.0005)$ & $(.0005)$ & (.0004) & $(.0008)$ & $(.0004)$ \\
\hline \multirow[t]{2}{*}{ lnHEATRATE } & -.463 & -.064 & -.498 & $-.548^{* *}$ & -.241 \\
\hline & $(.300)$ & $(.301)$ & $(.266)$ & $(.216)$ & $(.229)$ \\
\hline \multirow[t]{2}{*}{ WORKLOAD } & $.541 * *$ & .240 & .518 & .105 & $.579 * * *$ \\
\hline & $(.183)$ & $(.227)$ & $(.467)$ & $(.910)$ & $(.137)$ \\
\hline \multirow[t]{2}{*}{ INITIAL } & $2.60 \mathrm{e}-06$ & $2.20 \mathrm{e}-06$ & $2.31 \mathrm{e}-06$ & $3.16 \mathrm{e}-06$ & $-1.41 \mathrm{e}-07$ \\
\hline & $(2.30 \mathrm{e}-06)$ & $(2.94 \mathrm{e}-06)$ & $(2.41 \mathrm{e}-06)$ & $(4.09 \mathrm{e}-06)$ & $(1.32 \mathrm{e}-06)$ \\
\hline \multirow[t]{2}{*}{ MUNI $\Delta P_{e}$} & -.043 & .054 & -.041 & -.102 & -.057 \\
\hline & $(.049)$ & $(.220)$ & $(.173)$ & $(.071)$ & $(.045)$ \\
\hline CAP & - & $\begin{array}{r}-1.767 \\
(2.304)\end{array}$ & - & - & - \\
\hline CAP2 & - & $\begin{array}{r}.175 \\
(.215)\end{array}$ & - & - & - \\
\hline Constant & $\begin{array}{r}1.100 \\
(1.413)\end{array}$ & $\begin{array}{r}10.89 \\
(122.6)\end{array}$ & - & $\begin{array}{r}-5.280 \\
(4.782)\end{array}$ & $\begin{array}{r}4.089 * * \\
(1.219)\end{array}$ \\
\hline $\mathrm{R}^{2}$ & .226 & .046 & .228 & .301 & .201 \\
\hline Observations & 1586 & 1586 & 1552 & 1032 & 1291 \\
\hline
\end{tabular}

NotE: The dependent variable is $\left(B_{i[t+1]}-B_{i t}\right) / B_{i t}(\%)$. Columns (1) and (2) report estimation results from the fixed effects and random effects models. A Hausman test does not reject the null hypothesis; the error term $\alpha_{i}$ is correlated with the other explanatory variables. The test statistics are $\chi^{2}(19)=17.72$, Pvalue $=.5412$. Column (3) reports IV/2SLS estimation using natural gas wellhead price as an instrument for $\mathrm{SO}_{2}$ allowance price. Column (4) reports reduced sample estimation between (data from 1998 to 2003). Column (5) reports estimation results based on a balanced panel dataset, which restricts the sample to 145 units that were active from 1996 to 2004. Standard errors clustered by unit are reported in parentheses. *** indicates significant at the $1 \%$ level; ** indicates significant at the $5 \%$ level; * indicates significant at the $10 \%$ level. Reported $R^{2}$ is the adjusted $R^{2}$ for the fixed effects and random effects models and the centered $R^{2}$ for the IV/2SLS model. 
TABLE VI

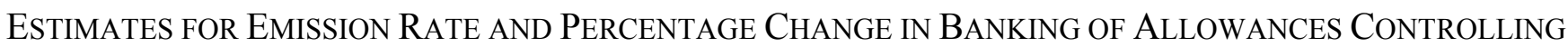
FOR UNITS’ DISTANCES TO PRB COAL

\begin{tabular}{|c|c|c|c|c|}
\hline \multirow[b]{2}{*}{ Variables } & \multicolumn{2}{|c|}{ Emission Rate } & \multicolumn{2}{|c|}{ Percentage Change in Allowance Stock } \\
\hline & (1) & (2) & (3) & (4) \\
\hline \multirow{2}{*}{$\Delta P_{e}$} & $-.838^{* *}$ & $-.832 * *$ & $2.590 * *$ & $2.642 * *$ \\
\hline & $(.342)$ & $(.348)$ & $(1.196)$ & $(1.924)$ \\
\hline \multirow[t]{2}{*}{$\ln \mathrm{P}_{\mathrm{a}}$} & -.043 & .002 & -.234 & -.836 \\
\hline & $(.056)$ & $(.003)$ & $(.122)$ & $(2.917)$ \\
\hline \multirow{2}{*}{$\ln \mathrm{P}_{\mathrm{e}}$} & $-.498 * *$ & $-.449 * *$ & .361 & .559 \\
\hline & $(.183)$ & (189) & $(.641)$ & (.669) \\
\hline \multirow[t]{2}{*}{ DPRB } & $.003 * *$ & $.003 * *$ & -.002 & -.002 \\
\hline & $(.001)$ & $(.001)$ & $(.002)$ & $(.002)$ \\
\hline \multirow[t]{2}{*}{ DPRB2 } & $-4.02 \mathrm{e}-06^{* *}$ & $-4.17 \mathrm{e}-09^{* *}$ & $1.63 \mathrm{e}-06$ & $1.51 \mathrm{e}-06$ \\
\hline & $(1.50 \mathrm{e}-06)$ & $(4.95 \mathrm{e}-10)$ & $(2.04 \mathrm{e}-06)$ & $(1.72 \mathrm{e}-06)$ \\
\hline \multirow[t]{2}{*}{ DPRB3 } & $1.32 \mathrm{e}-09 * *$ & $1.40 \mathrm{e}-09$ & $-4.88 \mathrm{e}-10$ & $-4.54 \mathrm{e}-10$ \\
\hline & $(4.97 e-10)$ & $(4.95 \mathrm{e}-10)$ & $(6.82 \mathrm{e}-10)$ & $(5.75 \mathrm{e}-10)$ \\
\hline \multirow[t]{2}{*}{ LSPremium } & $.170 * *$ & $.168 * *$ & .057 & .058 \\
\hline & $(.060)$ & $(.061)$ & $(.070)$ & $(.063)$ \\
\hline \multirow{2}{*}{ RetailAccess } & -.017 & $350.6^{* *}$ & .012 & -.084 \\
\hline & $(.041)$ & $(113.0)$ & $(.317)$ & $(.335)$ \\
\hline \multirow[t]{2}{*}{ Transit } & .078 & .085 & -.064 & -.122 \\
\hline & $(.085)$ & (.087) & (.299) & $(.313)$ \\
\hline \multirow[t]{2}{*}{ SCRUBBER } & $-1.87^{* *}$ & $-1.87 * *$ & .097 & .101 \\
\hline & $(.103)$ & $(.102)$ & $(.143)$ & $(.120)$ \\
\hline \multirow[t]{2}{*}{ AGE } & -.010 & -.012 & .051 & .042 \\
\hline & $(.016)$ & (.017) & $(.044)$ & $(.041)$ \\
\hline \multirow[t]{2}{*}{ AGE2 } & -.0002 & -.0002 & -.0008 & -.0007 \\
\hline & $(.0002)$ & $(.0002)$ & $(.0006)$ & $(.0005)$ \\
\hline \multirow[t]{2}{*}{ InHEATRATE } & $.349 * *$ & $.344 * *$ & -.111 & -.078 \\
\hline & $(.115)$ & $(.116)$ & (.318) & (.299) \\
\hline \multirow{2}{*}{ WORKLOAD } & -.099 & -.092 & .235 & .150 \\
\hline & $(.077)$ & $(.078)$ & $(.245)$ & $(.243)$ \\
\hline \multirow[t]{2}{*}{ INITIAL } & $1.21 \mathrm{e}-06$ & $1.23 \mathrm{e}-06$ & $2.08 \mathrm{e}-06$ & $1.63 \mathrm{e}-06$ \\
\hline & $(9.76 \mathrm{e}-07)$ & $(9.88 \mathrm{e}-07)$ & $(3.23 e-06)$ & $(3.20 \mathrm{e}-06)$ \\
\hline \multirow[t]{2}{*}{ MUNI $\Delta P_{e}$} & .142 & .141 & .053 & .070 \\
\hline & $(.104)$ & (.104) & $(.225)$ & (.196) \\
\hline \multirow[t]{2}{*}{ CAP } & -1.988 & -1.643 & -2.039 & -1.770 \\
\hline & (1.820) & $(1.840)$ & (2.544) & (2.163) \\
\hline \multirow[t]{2}{*}{ CAP2 } & .192 & .164 & .214 & .186 \\
\hline & $(.173)$ & $(.175)$ & $(.241)$ & $(.204)$ \\
\hline \multirow[t]{2}{*}{ constant } & $242.249 * *$ & 135.358* & -7.913 & - \\
\hline & (97.222) & (71.532) & (136.9) & \\
\hline $\mathrm{R}^{2}$ & .710 & .708 & .049 & .050 \\
\hline Observations & 1448 & 1425 & 1448 & 1425 \\
\hline
\end{tabular}

NotE: Columns (1) and (2) report results from estimating determinants of the log of the annual average emission rates identified in Eq.(30) via fixed effects and IV/2SLS (using natural gas wellhead prices as an instrument for $\mathrm{SO}_{2}$ allowance price). Columns (3) and (4) report similar regressions with the dependent variable being the percentage change of annual allowance banking from random effects and the IV/2SLS model. All estimations use units' distance to PRB coal as a proxy for low-sulfur coal price and include the low-sulfur coal premium as a repressor. Standard errors clustered by unit are reported in parentheses. ${ }^{* * *}$ indicates significant at the $1 \%$ level; $* *$ indicates significant at the $5 \%$ level; * indicates significant at the $10 \%$ level. Reported $R^{2}$ is the adjusted $R^{2}$ for the fixed effects and random effects models and the centered $R^{2}$ for the IV/2SLS model. 
Table VII

Banking Sensitivity Analysis for Values of Production Function Parameters and Input Costs

\begin{tabular}{|c|c|c|c|c|c|c|c|c|c|c|}
\hline & \multicolumn{2}{|c|}{$\theta=0.2$} & \multicolumn{2}{|c|}{$G=65$} & \multicolumn{2}{|c|}{$\alpha=0.5$} & \multicolumn{2}{|c|}{$\bar{~} P_{l}=130$} & \multicolumn{2}{|c|}{$\begin{array}{l}P_{h}=110 \\
\end{array}$} \\
\hline & $* q=0.2$ & $q=0.4$ & $\theta=0.2$ & $\theta=0.4$ & $\theta=0.2$ & $\theta=0.4$ & $\theta=0.2$ & $\theta=0.4$ & $\theta=0.2$ & $\theta=0.4$ \\
\hline 1995 & 0 & 0 & 0 & 0 & 0 & 0 & 0 & 0 & 0 & 0 \\
\hline 1996 & 1.14 & 1.19 & 0.07 & 0.98 & 1.04 & 1.87 & 1.75 & 2.34 & 1.66 & 2.27 \\
\hline 1997 & 2.44 & 2.57 & 0.31 & 1.9 & 2.25 & 3.67 & 3.6 & 4.7 & 3.44 & 4.59 \\
\hline 1998 & 3.93 & 4.15 & 0.84 & 2.88 & 3.67 & 5.62 & 5.56 & 7.14 & 5.33 & 6.99 \\
\hline 1999 & 5.62 & 5.9 & 1.91 & 4.28 & 5.3 & 7.71 & 7.62 & 9.65 & 7.33 & 9.46 \\
\hline 2000 & 7.5 & 7.85 & 3.53 & 6.04 & 7.16 & 9.94 & 9.78 & 12.23 & 9.46 & 11.99 \\
\hline 2001 & 6.1 & 6.47 & 2.13 & 4.64 & 5.73 & 8.8 & 8.55 & 11.36 & 8.19 & 11.1 \\
\hline 2002 & 4.88 & 5.28 & 1.2 & 3.54 & 4.5 & 7.78 & 7.41 & 10.56 & 7.04 & 10.29 \\
\hline 2003 & 3.84 & 4.26 & 0.6 & 2.72 & 3.47 & 6.89 & 6.37 & 9.82 & 5.99 & 9.52 \\
\hline 2004 & 2.98 & 3.4 & 0.22 & 2.13 & 2.63 & 6.11 & 5.45 & 9.13 & 5.05 & 8.8 \\
\hline 2005 & 2.26 & 2.68 & 0.01 & 1.72 & 1.95 & 5.44 & 4.63 & 8.5 & 4.24 & 8.14 \\
\hline 2006 & 1.7 & 2.11 & 0 & 1.44 & 1.43 & 4.86 & 3.89 & 7.9 & 3.52 & 7.54 \\
\hline 2007 & 1.28 & 1.65 & 0 & 1.23 & 1.07 & 4.36 & 3.26 & 7.35 & 2.9 & 6.99 \\
\hline 2008 & 0.99 & 1.3 & 0 & 1.09 & 0.82 & 3.93 & 2.72 & 6.84 & 2.4 & 6.49 \\
\hline 2009 & 0.78 & 1.06 & 0 & 0.99 & 0.64 & 3.56 & 2.26 & 6.38 & 1.97 & 6.03 \\
\hline 2010 & 0.65 & 0.89 & 0 & 0.91 & 0.52 & 3.24 & 1.89 & 5.93 & 1.61 & 5.61 \\
\hline 2011 & 0.56 & 0.77 & 0 & 0.86 & 0.44 & 2.96 & 1.57 & 5.52 & 1.34 & 5.21 \\
\hline 2012 & 0.5 & 0.69 & 0 & 0.83 & 0.38 & 2.72 & 1.31 & 5.13 & 1.12 & 4.85 \\
\hline 2013 & 0.44 & 0.63 & 0 & 0.8 & 0.34 & 2.52 & 1.12 & 4.76 & 0.98 & 4.49 \\
\hline 2014 & 0.41 & 0.58 & 0 & 0.77 & 0.31 & 2.34 & 0.97 & 4.39 & 0.87 & 4.13 \\
\hline 2015 & 0.38 & 0.55 & 0 & 0.74 & 0.28 & 2.17 & 0.85 & 3.99 & 0.77 & 3.74 \\
\hline 2016 & 0.35 & 0.52 & 0 & 0.69 & 0.25 & 2 & 0.75 & 3.54 & 0.68 & 3.32 \\
\hline 2017 & 0.29 & 0.46 & 0 & 0.61 & 0.21 & 1.79 & 0.65 & 3.05 & 0.59 & 2.86 \\
\hline 2018 & 0.23 & 0.4 & 0 & 0.47 & 0.15 & 1.51 & 0.53 & 2.51 & 0.48 & 2.36 \\
\hline 2019 & 0.11 & 0.27 & 0 & 0.26 & 0.07 & 1.08 & 0.36 & 1.82 & 0.33 & 1.7 \\
\hline 2020 & 0 & 0.03 & 0 & 0 & 0 & 0.43 & 0.1 & 0.85 & 0.09 & 0.78 \\
\hline
\end{tabular}

NOTE: The table shows simulation results for total amount of banked allowances (million tons) under different parameter values. * corresponds to the base case in which $\theta=0.2, q=0.2, G=55$, 